\title{
Neuronal Nicotinic Receptors in Sleep-Related Epilepsy: Studies in Integrative Biology
}

\author{
Andrea Becchetti \\ Department of Biotechnology and Biosciences, University of Milano-Bicocca, Piazza della Scienza 2, 20126 Milan, Italy \\ Correspondence should be addressed to Andrea Becchetti, andrea.becchetti@unimib.it
}

Received 25 September 2012; Accepted 21 October 2012

Academic Editors: L. S. Chang, P. Maher, and Y. Zhang

Copyright () 2012 Andrea Becchetti. This is an open access article distributed under the Creative Commons Attribution License, which permits unrestricted use, distribution, and reproduction in any medium, provided the original work is properly cited.

\begin{abstract}
Although Mendelian diseases are rare, when considered one by one, overall they constitute a significant social burden. Besides the medical aspects, they propose us one of the most general biological problems. Given the simplest physiological perturbation of an organism, that is, a single gene mutation, how do its effects percolate through the hierarchical biological levels to determine the pathogenesis? And how robust is the physiological system to this perturbation? To solve these problems, the study of genetic epilepsies caused by mutant ion channels presents special advantages, as it can exploit the full range of modern experimental methods. These allow to extend the functional analysis from single channels to whole brains. An instructive example is autosomal dominant nocturnal frontal lobe epilepsy (ADNFLE), which can be caused by mutations in neuronal nicotinic acetylcholine receptors. In vitro, such mutations often produce hyperfunctional receptors, at least in heterozygous condition. However, understanding how this leads to sleep-related frontal epilepsy is all but straightforward. Several available animal models are helping us to determine the effects of ADNFLE mutations on the mammalian brain. Because of the complexity of the cholinergic regulation in both developing and mature brains, several pathogenic mechanisms are possible, which also present different therapeutic implications.
\end{abstract}

\section{Introduction}

Strictly speaking, expressions like "integrative biology" or "system biology" are pleonastic, as the essence of biological processes is the interplay of many elements, even in unicellular organisms. Such locutions serve nonetheless to remind us that fully explaining physiological and pathological processes requires taking into account the organism context, which is easy to forget in a time that offers very powerful molecular methods. The pathogenesis of any disease is determined by a concourse of genetic, environmental, and developmental factors that produce their effects in a setting characterized by continuous interplay between cell groups, tissues, and organs. Understanding the conditions that predispose an individual to undergo such a course of events is thus a central problem of biology. Adopting a pathophysiological standpoint should considerably facilitate the task of gaining better integrative insight, because the experimental evidence related to pathology greatly exceeds the results available in other fields devoted to the organism biology. Therefore, although it seems unlikely that these issues will ever turn out to present general theoretical solutions, a more unified physiological comprehension of the biological individual would greatly advance our knowledge of virtually every aspect of general and applied biology, from the analysis of evolutionary constraints to the rational planning of therapy [1].

Genetic diseases are especially interesting in the present context, as they constitute the simplest biological perturbations of integrated physiological systems. Particularly amenable to experimental study are those diseases caused by mutant ion channels (channelopathies $[2,3]$ ), because methods are available to investigate the effects of these mutations at all the relevant hierarchical levels. For example, in the case of a neurologic disease, whole brains can be studied by functional imaging and electroencephalography (EEG). Single cerebral nuclei and the interactions between nuclei can be studied by stimulating and recording in different sites by using single-cell or multisite recording techniques. Neural circuits can be also studied in vitro by applying similar methods to brain slice preparations, perhaps retaining part 
TABLE 1: Ionotropic ACh and GABA receptors. Nomenclature and related monogenic epilepsies.

\begin{tabular}{|c|c|c|c|}
\hline Receptor & Subunit & Gene & Epilepsy \\
\hline \multirow{5}{*}{ Muscle nAChR } & $\alpha_{1}$ & CHRNA1 & \\
\hline & $\beta_{1}$ & CHRNB1 & \\
\hline & $\gamma$ & CHRNG & \\
\hline & $\delta$ & CHRND & \\
\hline & $\varepsilon$ & CHRNE & \\
\hline \multirow{7}{*}{ Neuronal nAChR } & $\alpha_{2}$ & CHRNA2 & \multirow[t]{2}{*}{ Sleep-related epilepsy } \\
\hline & $\alpha_{3}$ & CHRNA3 & \\
\hline & $\alpha_{4}$ & CHRNA4 & \multirow[t]{2}{*}{ ADNFLE } \\
\hline & $\alpha_{5}-\alpha_{10}$ & CHRNA5-CHRNA10 & \\
\hline & $\beta_{2}$ & CHRNB2 & \multirow[t]{3}{*}{ ADNFLE } \\
\hline & $\beta_{3}$ & CHRNB3 & \\
\hline & $\beta_{4}$ & CHRNB4 & \\
\hline \multirow{13}{*}{ GABA receptors } & $\alpha_{1}$ & GABRA1 & \multirow{13}{*}{ FS, CAE, DS, GEFS+ } \\
\hline & $\alpha_{2}-\alpha_{6}$ & GABRA2-GABRA6 & \\
\hline & $\beta_{1}$ & GABRB1 & \\
\hline & $\beta_{2}$ & GABRB2 & \\
\hline & $\beta_{3}$ & GABRB3 & \\
\hline & $\gamma_{1}$ & GABRG1 & \\
\hline & $\gamma_{2}$ & GABRG2 & \\
\hline & $\gamma_{3}$ & GABRG3 & \\
\hline & $\delta$ & GABRD & \\
\hline & $\varepsilon$ & GABRE & \\
\hline & $\theta$ & GABRQ & \\
\hline & $\rho_{1}-\rho_{3}$ & GABRR1-GABRR3 & \\
\hline & $\pi$ & GABRP & \\
\hline
\end{tabular}

Legend. ADNFLE: autosomal dominant nocturnal frontal lobe epilepsy; CAE: childhood absence epilepsy; DS: Dravet syndrome; GEFS+: generalized epilepsy with febrile seizures plus; JME: juvenile myoclonic epilepsy. For reference about GABA receptors and epilepsy, see [48].

of the global connections, as in thalamocortical preparations. These methods can be applied down to the single cell and, if necessary, even the single protein (by applying single-channel recording methods to primary cultures or suitable expression systems). In practice, however, interpreting the results obtained by these methods in a coherent way is far from easy, for at least two reasons. First, the spectrum of necessary competences is very wide and the communication between researchers with different backgrounds is not always easy. Second, the results obtained at a given level may be difficult to interpret at another level. For instance, observing that a given mutant ion channel shows decreased function in ex vivo expression does not immediately suggest whether and how this features will be translated into hyper- or hypoexcitability in vivo. This is because this channel type could be simultaneously expressed in different brain regions, in both excitatory and inhibitory cells, and perhaps in different cell compartments (e.g., pre- and postsynaptic). As will be clear from the sections below, the result of such complexity is that the experimental data obtained at different levels of biological organization can sometimes appear contradictory. Use of different species only adds to the complexity. Nevertheless, ever more intense efforts to combine different approaches seems inescapable to maintain the hope of integrating in a sensible way the wealth of results available on the micro- and macroscopic features of the biological system.

Many cases are known of ion channel genes linked to epilepsy among both voltage-gated and ligand-gated ion channels [2]. In the case of the latter, the relationship between mutant receptors and the pathogenesis is often even less straightforward than it is for voltage-gated channels. Several mendelian epilepsies (Table 1) are known to be caused by mutant genes coding for neuronal nicotinic receptors (nAChRs) and $\mathrm{GABA}_{\mathrm{A}}$ receptors $\left(\mathrm{GABA}_{\mathrm{A}} \mathrm{Rs}\right.$; [3]), although, somewhat curiously, not for ionotropic glutamate receptors [4]. I here focus on ADNFLE, a sleep-related epilepsy linked to mutant $\mathrm{nAChR}$ receptors $[2,5]$. Because of the possible relation between cholinergic and GABAergic transmission in ADNFLE and the general importance of inhibitory transmission in epilepsy [6], the main aspects of GABAergic system will be also briefly reviewed. After describing the main features of $\mathrm{nAChRs}$ and $\mathrm{GABA}_{\mathrm{A}}$ Rs, I will give a broad introduction to the physiology of sleep-waking cycle, and the main anatomical and functional aspects of the cerebral cholinergic and GABAergic systems. Next, I will describe the specific characteristics of ADNFLE, what is known about 
Subunit topology

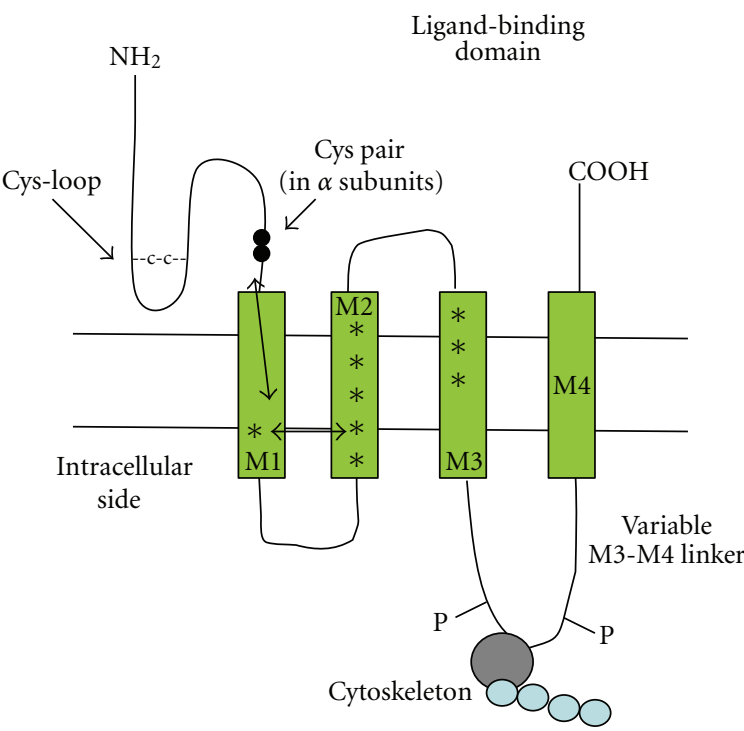

(a)
Subunit assembly

(viewed from top)

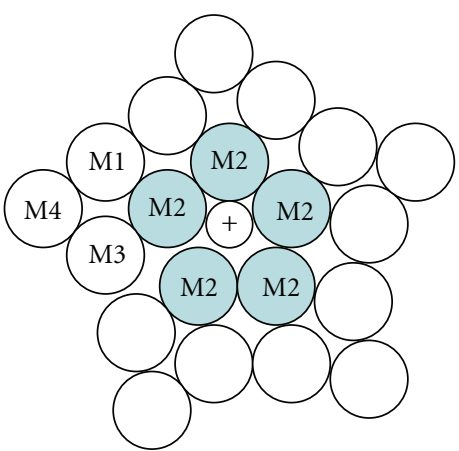

(b)

FIGURE 1: Schematic of the location of ADNFLE mutations within the nAChR subunit structure. (a) overall topology of the typical nAChR subunit; asterisks mark the location of the mutations listed in Table 2. Double arrows mark the probable transduction pathway between the ligand-binding pocket and the M2 segment, which constitutes at the same time the channel gate and the selectivity filter. The panel also shows the location of the Cys-loop and the Cys pair that defines the $\alpha$ subunits. The M3-M4 variable linker is implicated in channel interaction with the cytoskeleton and regulation by phosphorylation. (b) probable arrangement of the M1-M4 segments of the five subunits constituting the pentameric receptor. The M2 segments line the channel pore. On agonist binding, the ligand pocket partially rotates. Such conformational change is transferred to the M2 segments, whose rotation removes from the channel lumen several hydrophobic amino acid side chains. In this way, the pore diameter widens from about $0.3 \mathrm{~nm}$ to approximately $0.8 \mathrm{~nm}$. This enlargement is accompanied by the movement of hydrophilic groups into the lumen. The overall effect is considerable increase in ion permeability. For introduction to the structure-function studies on nAChRs, see $[7,8,12,14,15]$.

the mutations so far identified, and the currently available animal models of this disease. Finally, I will summarize the potential pathogenic mechanisms as well as the open questions.

\section{Cys-Loop Family Receptors}

The nicotinic and the $\mathrm{GABA}_{\mathrm{A}}$ receptors belong to a structural family of ion channels that also comprises the 5hydroxytryptamine (serotonin)-gated type 3 receptors (5$\mathrm{HT}_{3} \mathrm{R}$ ) and the strychnine-sensitive glycine receptors. All of these are pentameric ion channels, permeable to either cations (nAChRs and 5-HT3Rs) or anions (GABA and glycine receptors). The general subunit structure is similar to the one determined for nAChRs, with a large extracellular $\mathrm{N}$-terminal domain containing the ligand-binding site, four consecutive hydrophobic transmembrane domains (named M1-M4, or TM1-TM4), and a short variable extracellular Cterminus (Figure 1). Subunits can be equal or different and their stoichiometry is highly variable. Many subunits present splice variants. The name "Cys-loop" derives from the presence of a disulphide bridge which delimits 13 conserved amino acid residues forming a loop at the base of the extracellular domain (Figure 1). The Cys-loop participates in transducing the ligand-binding signal to the pore $[7,8]$. In addition, the $\alpha$ subunits are defined by the presence of a CysCys pair (Figure 1) in the N-terminal domain (e.g., amino acids 191 and 192 in the Torpedo nAChR sequence). This couple of Cys residues is necessary for ACh binding [8].

Most of what we know about Cys-loop receptors comes from studies in the nervous system and the neuromuscular junction. However, increasing evidence indicates that these receptors, particularly nAChRs [9] and $\mathrm{GABA}_{\mathrm{A}}$ Rs [10], are also significantly expressed in nonneuronal tissue, where their physiological roles are still matter of debate [9-11].

2.1. nAChRs. The nAChR [12] was discovered in the endplate postsynaptic membrane and first purified and cloned from the electroplaques of Torpedo californica. The history of $\mathrm{nAChR}$ purification, cloning, and structural characterization is an epitome of the development of concepts and methods related to ionotropic receptors $[13,14]$ and cannot be fully discussed here. In brief, the muscle receptor's stoichiometry in adult tissue is typically $\left(\alpha_{1}\right)_{2} \beta_{1} \varepsilon \delta$. During development, the $\varepsilon$ subunit is substituted by $\gamma$. Therefore, in muscle receptors, two binding sites for $\mathrm{ACh}$ are formed by the amino acid residues located at the interfaces between $\alpha$ and $\varepsilon / \gamma$ [12]. The nAChR is also widely expressed in the nervous 
system. To date, nine $\alpha(\alpha 2-\alpha 10)$ and three $\beta(\beta 2-\beta 4)$ neuronal subunits have been cloned. The corresponding genes are named CHRNA2-CHRNA10, and CHRNB2-CHRNB4 (Table 1). Subunits $\alpha 2-\alpha 6$ and $\beta 2-\beta 4$ can associate to form heteromeric $\alpha \beta$ nAChRs, with various possible stoichiometries $[12,15]$. In contrast, the $\alpha 7-\alpha 9$ subunits usually form homopentameric receptors. By far the most widespread is $(\alpha 7)_{5}$, whereas $\alpha 8$ is restricted to avians and $\alpha 9$ and $\alpha 10$ are mainly expressed in the cochlea. However, recent evidence indicates that these subunits can also form heteromeric receptors. For example, $\alpha 9$ can associate with $\alpha 10$ [15]. Moreover, studies in expression systems show that $\alpha 7$ can associate with $\beta 2$, even though the physiological relevance in vivo is unknown $[16,17]$. The functional meaning of such a combinatorial diversity is unclear. In the mammalian brain, the heteropentamer $\alpha 4 \beta 2$ and the homopentamer $(\alpha 7)_{5}$ seem to be the most common forms, at least in rodents [18], but the contribution of the other subunits is under intense investigation. For example, recruitment of $\alpha 5$ is known to modulate the properties of $\alpha 4 \beta 2$ receptors [19]. Moreover, a widespread expression of $\alpha 2$ has been observed in both primates $[20,21]$ and rodents [22]. As to $\beta 4$, it is also widely expressed in the mammalian neocortex of squirrel monkeys [23] and adult mice [24] and is equally distributed throughout the brain in human feti and aged postmortem samples [25]. The subunit expression in different cerebral regions and nuclei is species specific; for example, $\alpha 2$ is scarcely expressed in the murine thalamus [22] but highly expressed in human thalamic samples [21]. In the peripheral nervous system, there is a prevalent contribution of $\alpha 3$ and $\beta 4$ [26].

The overall structure of the neuronal and muscle isoforms is similar. Each subunit is constituted by a continuous polypeptide comprising approximately 500 to 600 amino acid residues. Pseudocrystalline forms of the Torpedo receptors [27] and X-ray crystallographic structures of the AChbinding proteins produced by several snail species have given considerable insight into the nAChR structure $[7,8,12]$. From these studies it was inferred that these ion channels have a wide extracellular water-filled vestibule with a diameter of approximately $2 \mathrm{~nm}$, formed by the long (about 200 amino acids) $\mathrm{N}$-terminal extracellular domains of the five subunits. The N-terminal segment of each subunit presents a $\beta$-barrel structure and is followed by 4 transmembrane domains (M1-M4, or TM1-TM4). The M2 domains of the five subunits line the conduction pore and form the channel gate [28]. The variable intracellular domain between M3 and M4 is generally longer than the M1-M2 loop. It mediates channel regulation by phosphorylation $[29,30]$ and interacts with other cytoplasmic constituents, such as the cytoskeleton ([31]; Figure 1). The short C-terminal domains are also extracellular and present variable lengths. As is typical of ligand-gated channels as well as other allosteric proteins, at least two agonist molecules need to bind the receptor to produce significant probability that the channel is open [32]. The number of ligand-binding sites depends on subunit stoichiometry. In particular, agonists bind to a molecular crevice formed at the interface between each $\alpha$ subunit and the adjacent subunit. A good part of the binding region is contributed by the so-called C-loop in the $\alpha$ subunit, which contains the Cys-Cys pair. Other specific amino acid residues of both the involved subunits contribute to ligand binding. However, because of altered sequence, subunits $\alpha 5, \alpha 10$, $\beta 1$, and $\beta 3$ cannot participate in the agonist-binding site, although their presence regulates the nAChR properties [12]. In general, the total number of agonist molecules that bind to the receptor depends on the number of $\alpha$ subunits that contain an effective ligand-binding structure. For example, five agonist molecules can bind to $(\alpha 7)_{5}$ receptors whereas only two can bind to $(\alpha 4)_{2}(\beta 2)_{3}$ receptors $([15])$. Further structural details about channel gating are given in the legend to Figure 1.

Homo- and heteropentameric nAChRs show clear functional differences. First, homomeric receptors display higher permeability to $\mathrm{Ca}^{2+}$. In $\alpha 7$ receptors, the permeability ratio between $\mathrm{Ca}^{2+}$ and $\mathrm{Na}^{+}$is about 10 , whereas it is approximately 2 in $\alpha 4 \beta 2$ receptors [33]. Moreover, in the presence of agonists, homomeric receptors desensitize more quickly and deeply than the heteromeric. Although the precise kinetics of current decay depend on subunit composition, all heteromeric nAChRs tend to display significant steady state currents in the presence of low agonist concentrations [15]. Another broad distinction between homo- and heteromeric nAChRs concerns pharmacology. The apparent affinity of $\alpha 7$ receptors for $\mathrm{ACh}$ and nicotine is low, with $\mathrm{EC}_{50}$ of about 100 to $200 \mu \mathrm{M}$. Heteromeric receptors have instead higher affinities. For instance, the apparent $\mathrm{EC}_{50}$ of $\alpha 4 \beta 2 \mathrm{nAChRs}$ is about $30 \mu \mathrm{M}$ for $\mathrm{ACh}$. This value is however somewhat misleading, as different subunit stoichiometries present different sensitivity to ligands. In particular, the concentrationresponse relation for $\mathrm{ACh}$ and nicotine of $\alpha 4 \beta 2$ receptors presents a high- and a low-affinity component, with $\mathrm{EC}_{50} \mathrm{~s}$ of about $1 \mu \mathrm{M}$ and $60 \mu \mathrm{M}[34,35]$. These two components are, respectively, attributed to the coexistence of $(\alpha 4)_{2}(\beta 2)_{3}$ and $(\alpha 4)_{3}(\beta 2)_{2}$ receptors, which account for approximately $20 \%$ and $80 \%$ of the observed currents $[36,37]$.

2.2. $G A B A_{A}$ Rs. The GABA receptors constitute an even wider subfamily, comprising the ionotropic $G_{A B A}$ and the metabotropic $\mathrm{GABA}_{B}$ receptors. $\mathrm{GABA}_{\mathrm{A}}$ Rs (generally inhibited by bicuculline [38]) are heteropentamers of a variety of subunits, the main being $\alpha_{1}-\alpha_{6}, \beta_{1}-\beta_{3}, \gamma_{1}-\gamma_{3}$, and $\delta$ [39]. The corresponding genes are named, respectively, GABRA1A6, GABRB1-B3, GABRG1-G3, and GABRD (Table 1). Additional subunits with more localized expression include $\varepsilon$ (GABRE), $\theta$ (GABRQ), and $\pi(G A B R P)$. The most common subunit stoichiometry is $2 \alpha 2 \beta \gamma(\delta)$. In addition, rho subunits $\rho_{1}-\rho_{3}$ (GABRR1-R3) are also known. Receptors containing a $\rho$ subunit are sometimes called $\mathrm{GABA}_{\mathrm{C}}$, which are mainly expressed in the retina and are insensitive to bicuculline. About $60 \%$ of the $\mathrm{GABA}_{\mathrm{A}}$ Rs in the brain are constituted by the $\alpha_{1} \beta_{2} \gamma_{2}$ subunits. Other common forms are $\alpha_{1} \beta_{2 / 3} \gamma_{2}$, $\alpha_{2} \beta_{3} \gamma_{2}$ and $\alpha_{3} \beta_{3} \gamma_{2}$ [40]. The general structure and the molecular determinants of channel assembly and interaction with other proteins are broadly similar to those observed in nAChRs $[7,8,31]$.

$\mathrm{GABA}_{\mathrm{A}} \mathrm{Rs}$ are permeable to anions. In physiological conditions, $\mathrm{Cl}^{-}$is the main permeant anion, but $\mathrm{HCO}_{3}{ }^{-}$also gives a significant contribution (e.g., [41]). In the adult, these 
channels determine the rapid postsynaptic inhibitory currents, particularly in the brain. In brainstem and spinal cord the structurally and functionally related Gly receptors tend to prevail [42]. However, certain subsets of inhibitory synapses may synthesize and corelease GABA and Gly, to generate even more complex postsynaptic responses $[43,44]$. Both $\mathrm{GABA}_{\mathrm{A}}$ and Gly receptors can be potentiated by a variety of extracellular agents, such as alcohols [45] and neurosteroids [46]. When the intracellular $\mathrm{Cl}^{-}$concentration $\left(\left[\mathrm{Cl}^{-}\right]_{i}\right)$ reaches sufficiently high values, the reversal potential of $\mathrm{GABA}_{\mathrm{A}}$ currents can make the GABAergic stimulus excitatory instead of inhibitory. This is known to occur during the development of the nervous system (see also Section 11.2). In rodents, during the second week of postnatal development, the membrane transporter NKCC (which extrudes one $\mathrm{K}^{+}$and absorbs one $\mathrm{Na}^{+}$and two $\mathrm{Cl}^{-}$) is substituted by KCC (which extrudes $\mathrm{KCl}$ ), which is typical of the adult brain [38]. Because of the expression of different $\mathrm{Cl}^{-}$transporters during brain development, in early stages the ratio $\left[\mathrm{Cl}^{-}\right]_{o} /\left[\mathrm{Cl}^{-}\right]_{i}$ is smaller than in the mature circuits. In these conditions, activating $\mathrm{GABA}_{\mathrm{A}}$ receptors has depolarizing (and thus excitatory) effects. Whether a similar mechanism is also operant in the adult brain, in certain circumstances, is still matter of debate [47].

Several idiopathic epileptic forms are caused by mutations on genes coding for $\mathrm{GABA}_{\mathrm{A}} \mathrm{R}$ subunits. These are summarized in Table 1 and were recently reviewed in [48]. In brief, mutations in GABRA1 have been found to be linked to juvenile myoclonic epilepsy (JME) and childhood absence epilepsy (CAE); mutations on GABRB3 can cause CAE; mutant GABRG2 genes can be linked to febrile seizures (FS), CAE, Dravet syndrome (DS), or generalized epilepsy with febrile seizures plus (GEFS+). Finally, mutations on GABRD have been found to be linked to FS and GEFS+ [48].

\section{The Sleep Stages}

Sleep is a complex physiological state with distinct phases defined, in mammals and avians, by simultaneous use of EEG, electrooculography, and electromyography. The following discussion is based on references $[49,50]$ and summarizes the aspects relevant to the present purposes. EEG monitors the voltage fluctuations measured by electrodes applied onto the scalp. The EEG traces are determined by the coordinated activity of the thalamocortical system, which generates complex waves containing low- and high-frequency components. The electrooculogram and electromyogram register, respectively, the eye movements and the skeletal muscle tone, which further characterize specific sleep stages. A graph showing the duration and timing of sleep states is named hypnogram. During attentive wakefulness, EEG mostly comprises low-voltage $(5-10 \mu \mathrm{V})$, highfrequency $(20-40 \mathrm{~Hz})$ waves (beta rhythm). On relaxed waking, slightly ampler waves with lower frequency (about $10 \mathrm{~Hz}$ ) tend to prevail (alpha rhythm). On falling asleep, alpha waves are substituted by mixed EEG waves, with frequency range similar to the beta's but somewhat higher amplitude. This phase is named stage 1 sleep. It only lasts a few minutes and is accompanied by slow, drifting eye movements. During the following stage 2 sleep, the EEG waves of stage 1 are punctuated by so-called $K$-complex and sleep spindle waves. The former are sharp, high-voltage transient waves which occur spontaneously or may be triggered by sensory stimulus. The sleep spindles are wave bursts (12 to $15 \mathrm{~Hz}$ ) lasting 1 to $2 \mathrm{~s}$, characterized by higher voltage amplitudes in the middle of the burst. This gives a spindle shape to the envelope of such waves. Stage 2 lasts about $30 \mathrm{~min}$ and shows no rolling eye movements. Progressively (stage 3 ), sleep spindles become more frequent and the background waves between spindles assume a higher amplitude (up to $300 \mu \mathrm{V})$ and a lower frequency $(0.5$ to $3 \mathrm{~Hz})$. These are called delta waves. During the subsequent stage 4 sleep, delta waves predominate and spindles may disappear. Stages 3 and 4 of sleep are collectively named slow wave sleep (SWS), because of the prominent delta waves that reflect the synchronous activity of large populations of neurons. Stage 1 to stage 4 are collectively named non rapid eye movement (NREM) sleep, as no rapid eye movements are revealed by electrooculography. In humans, stage 4 begins approximately $1 \mathrm{~h}$ after sleep onset and lasts 20 to $30 \mathrm{~min}$. Subsequently, the sleeper reverts to stage 3 and stage 2, from which a further state (rapid eye movement, or REM, sleep) can be abruptly reached. REM sleep is characterized by the beta waves typical of the waking state, but the individual is asleep and presents rapid eye movements. Moreover, the skeletal muscle tone reaches its minimum here, with diffuse peripheral paralysis. REM sleep is thought to comprise most of the oneiric activity. Its EEG waves reflect the fact that cortical neurons tend to follow an activity pattern similar to that observed in waking, with neurons not recruited in large synchronized populations. It should be however recalled that during wakefulness and REM sleep a low-voltage rhythm around $40 \mathrm{~Hz}$ (gamma) is observed. Many authors believe the gamma rhythm to reflect the temporal binding of activity in distributed neural circuits that participate in coordinated functions [51-58]. For this and other reasons, the terms synchronized and desynchronized sleep, sometimes used to refer, respectively, to SWS and REM sleep, are somewhat misleading [59].

In humans, several of the above NREM plus REM cycles take place during a typical nocturnal sleep, interspersed by occasional awakenings. Sleep in nonhuman mammals does not comprise exactly the same stages and is more simply described in terms of SWS and REM sleep, with durations and cycle times shorter than in humans. This is important to notice considering the widespread use of animal models of neuropathology. Moreover, voltage amplitudes can be higher when the EEG electrodes are placed directly onto the cerebral cortex of experimental animals, to perform the so-called electrocorticography [49].

\section{Regulation of the Sleep-Waking Cycle}

Moruzzi and Magoun first observed that the brainstem reticular formation maintains cortical activation and behavioral arousal during wakefulness [60]. This effect is determined by ascending stimulation of the neocortex and descending regulation of behavioral arousal and muscle tone. Neocortex activation depends on three main groups of brainstem cells: 
glutamatergic pontomesencephalic nuclei, cholinergic cells (laterodorsal and pedunculopontine tegmental nuclei), and noradrenergic (locus coeruleus) nuclei [61-63]. These nuclei exert their ascending physiological effects by following two anatomical pathways. First, they project their fibers dorsally to the thalamus, thus stimulating the nonspecific thalamocortical glutamatergic cells in the midline and intralaminar nuclei [64]. Second, they project ventrally to regulate the histaminergic cells located in the tuberomammillary hypothalamic nuclei [65] and the cholinergic and glutamatergic cells located in the basal forebrain [61]. In turn, these relay stations send diffuse projections to the neocortex and can maintain cortical activation even in the absence of the brainstem input [61]. The locus coeruleus also diffusely innervate the forebrain, brainstem, and spinal cord with noradrenergic fibers $[61,62]$.

Such an ensemble of interplaying nuclei is often referred to as ascending reticular activating system. A simplified scheme is given in Figure 2. Although a certain redundancy is apparent in this system, the function and the timing of activity of the different nuclei are not identical. Neurons in locus coeruleus maximally discharge during active waking, decrease firing during SWS, and stop firing during REM sleep [66]. In contrast, high cholinergic drive (from both pontomesencephalic and basal forebrain nuclei) is observed during both waking and REM sleep, but not during SWS [62, 67-69]. ACh release is thought to be mainly involved in neocortical activation but not behavioral arousal. Therefore, simultaneous activation of cholinergic and noradrenergic cells is necessary to sustain a waking state with both cortical activation and muscle tone. During sleep, high cholinergic activity accompanied by decreased noradrenergic tone (and lower activity of the other arousal systems) favors the transition to REM sleep, in which motor activity is largely impeded [70].

The other transmitter systems cooperate in this complex regulatory pattern. Serotonergic neurons in the brainstem raphe nuclei show a discharge pattern similar to the cholinergic, but the functional role is not identical, as serotonergic cells seem to be mainly implicated in less-aroused waking states [71]. They can also attenuate cortical activation by inhibiting stronger activators, such as the cholinergic cells themselves [61, 62]. Dopaminergic neurons of the substantia nigra and ventral tegmentum project to the striatum, basal forebrain, and cortex. They probably stimulate arousal in relation to the experience of positive emotions during both waking and REM sleep, while they do not seem to regulate behavioral arousal and muscle tone [72, 73]. The complexity and subtleness of the overall system are further enhanced by the reciprocal interactions of the above pathways. For example, noradrenergic fibers from the locus coeruleus innervate other brainstem nuclei and basal forebrain cells (including the cholinergic, $[61,62])$. The arousal-controlling nuclei in brainstem, basal forebrain, and hypothalamus are also modulated by peptidergic control, particularly by hypocretin (orexin) releasing fibers [74-79]. Hypocretin neurons are located in the lateral hypothalamus; they mostly discharge during active waking and stop firing during sleep [80, 81]. Consistently, disruption of the orexin system leads to the sleep disorder narcolepsy with cataplexy in humans as well as in animal models [82-84].

The other side of the sleep-waking coin is sleep promotion. Several lines of evidence indicate that most GABAergic neurons in the basal forebrain [85-88] and preoptic area [88-90] have higher activity during SWS and cortical lowactivity states (or sleep recovery). These cells are also named cortical activation-off and are thought to be necessary to induce sleep $[91,92]$. Some of them project to the neocortex $[93,94]$, whereas others project locally or to the hypothalamus or brainstem [62]. A lower fraction of GABAergic cells in these regions presents instead cortical activationon features [95]. In fact, basal forebrain GABAergic cells appear to be functionally heterogeneous. Some maximally discharge during wake and REM sleep, other discharge maximally during SWS, and still other progressively increase their activity during sleep, to maximally discharge during REM, in association with low electromyographic activity [96]. GABAergic cells in forebrain and preoptical area seem also to regulate hypocretin $[97,98]$ and histaminergic [91] cells in the hypothalamus as well as adrenergic cells of the locus coeruleus [91]. These cells are in their turn regulated by noradrenergic input [62]. GABAergic cells in brainstem and thalamus also appear to be active during sleep to inhibit wake-active neurons. The role of GABAergic cells in the reticular nucleus of thalamus (RT) will be described later.

\section{The Cellular Basis of EEG in Sleep and Epilepsy}

We briefly review the main cellular determinants of the EEG activity during sleep and the implication for seizure facilitation. More extensive treatment is found in [50, 59, 99-101].

\subsection{NREM Sleep}

5.1.1. Mechanism of Rhythmic Burst Firing in Single Neurons. During NREM sleep, the decrease of ascending excitation hyperpolarizes thalamic and neocortical neurons (up to approximately $-80 \mathrm{mV}$ ). Hyperpolarization favors the development of action potential bursts, particularly in thalamic cells, which are said to enter the burst mode of firing [102]. A more negative resting $V_{m}$ removes inactivation from T-type (or low-threshold) voltage-gated $\mathrm{Ca}^{2+}$ channels $\left(I_{\mathrm{CaT}}\right.$; [103107]). Such a deinactivation makes $I_{\mathrm{CaT}}$ ready to activate on depolarization, thus producing a low-threshold calcium spike, whose amplitude and duration are sufficient to trigger a series of classical $\mathrm{Na}^{+}$-dependent action potentials [102, $108,109]$. After a burst, the cell returns to rest because of the activation of voltage- and $\mathrm{Ca}^{2+}$-activated $\mathrm{K}^{+}$currents. Next, at negative $V_{m}$, inactivation is again removed from $I_{\text {CaT }}$. Moreover, hyperpolarization-activated cation currents $\left(I_{H}\right)$ can produce a relatively slow depolarization $[110,111]$, resembling the cardiac pacemaker, which can trigger another burst. This mechanism can thus give rise to rhythmic burst firing $[112,113]$.

5.1.2. Sleep Spindles. Sleep spindles are generated by activity of the RT nucleus, which can produce spindle-like rhythms 


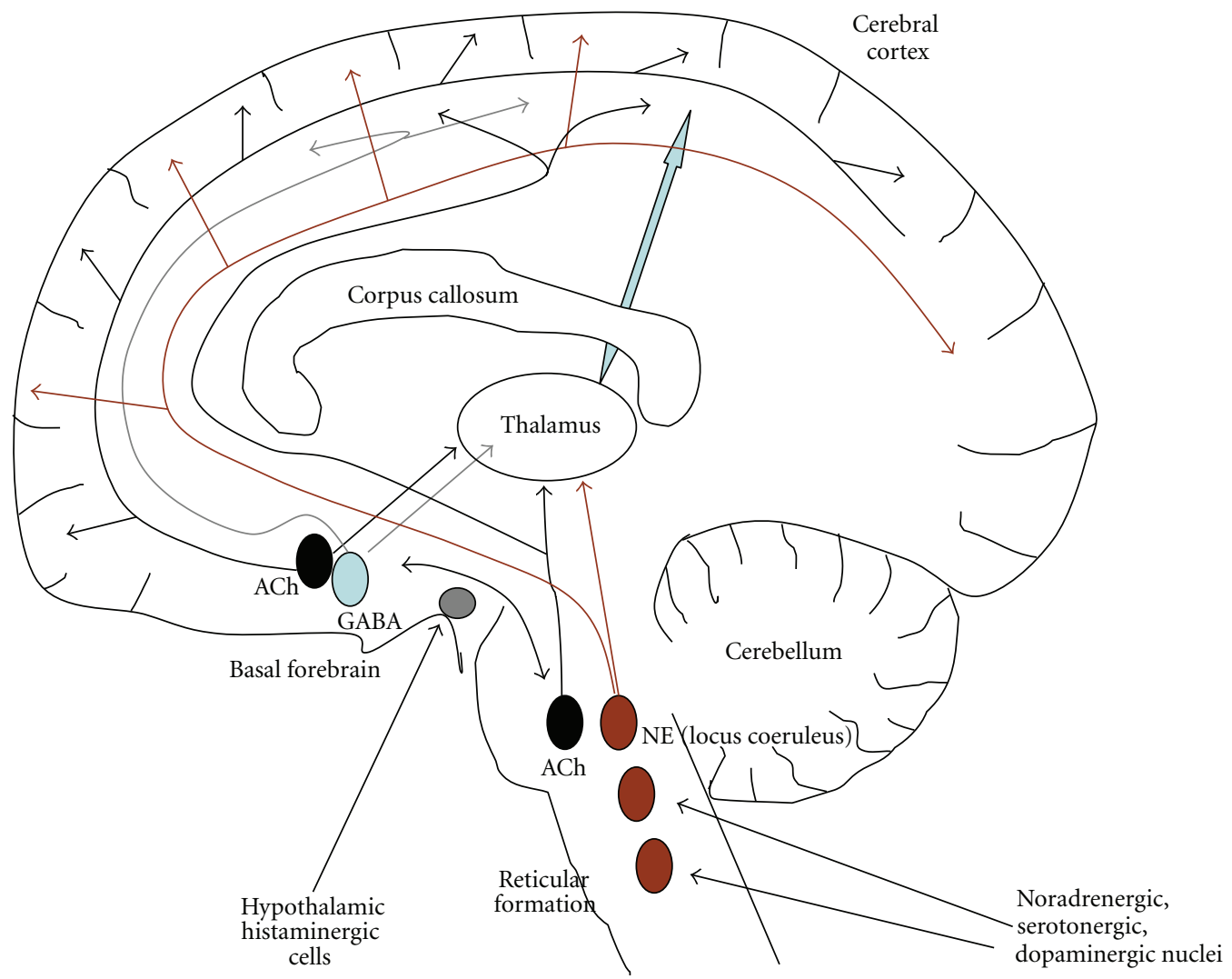

FIGURE 2: Simplified scheme of the ascending modulatory systems in the brain. The picture recapitulates the main ascending modulatory systems, with no pretension of neuroanatomical precision. Black (ACh): pontomesencephalic and basal forebrain cholinergic nuclei; light blue (GABA): GABAergic nuclei in the forebrain; brown: several noradrenergic (the main being locus coeruleus), dopaminergic, and serotonergic nuclei which cooperate in regulating the brain active states (see the main text); gray: hypothalamic histaminergic cells, which also regulate cortical activation. For clarity no connection pattern is shown for histaminergic, serotonergic, and dopaminergic nuclei. NE: norepinephrine.

even in isolation $[114,115]$. Nonetheless, the neocortex activity determines spindle synchronization and simultaneous appearance over wide regions [116]. The spindle rhythm depends on the frequency of spike bursts in GABAergic RT cells, generated as described in Section 5.1.1. As a consequence, RT neurons induce rhythmic inhibitory postsynaptic potentials (IPSPs) in thalamocortical neurons, which may lead to postinhibitory rebound spike bursts, by a mechanism analogous to the one described above. Because thalamocortical cells are excitatory, their burst activity stimulates rhythmic excitatory postsynaptic potentials (EPSPs) on neocortical cells. Occasionally, these EPSPs trigger action potentials, and more likely so during the middle portion of the EPSP train. Such a pattern gives to the overall EEG wave the typical spindle form, with higher voltage amplitude in the central phase [59]. During sleep, a large fraction of time is spent by thalamocortical neurons in spindle-related IPSPs. Therefore, these neurons are not available to transmit sensory inputs to the cerebral cortex, whereas cortico-cortical and corticothalamic dialogue may be maintained during sleep [117].

Although not receiving sensory stimuli, cortical neurons are actually very active during NREM sleep and overexcitation during spindles has been found to potentiate synaptic responsiveness $[118,119]$. This may contribute to consolidate the memory traces acquired during wakefulness. What is more relevant in the present context, the spindlerelated potentiation can lead to epileptiform activity [119]. Stimulating the thalamus and cortex with spindle-like frequencies tends to produce strong intertrain depolarizing events that can lead to paroxysmal oscillations. This phenomenon can be observed in the neocortex even in the absence of thalamus [120]. In general, seizures with spikewave or polyspike-wave complexes tend to occur during NREM sleep. The potential relevance of these observation for ADNFLE are discussed later.

5.1.3. Delta Waves. The delta waves, typical of SWS, present both a cortical and a thalamic component that can be observed independently [59]. In intact brains, however, corticothalamic volleys synchronize the thalamocortical cells through the inhibition produced by RT cells. These set the thalamocortical $V_{m}$ at the negative value best to generate delta oscillations. Moreover, they also synchronize the dorsal thalamus. Interestingly, delta waves appear at more hyperpolarized level than spindles, in thalamocortical cells [121]. Therefore, these two rhythms are scarcely compatible. During the course of sleep, the progressive hyperpolarization of thalamocortical cells driven by the decrease in activity 
of cholinergic and other ascending activating fibers tends to make spindles disappear in favour of slow waves. The effect is reverted before the onset of REM sleep, in which thalamocortical cells tend to depolarize because of increased drive from brainstem $[59,101]$.

5.1.4. Slow EEG Oscillation. Cortical neurons tend to exhibit cycles of spontaneous depolarizations and hyperpolarizations that produce a slow $0.7-0.8 \mathrm{~Hz} V_{m}$ oscillation [120, 122, 123]. This pattern also occurs during SWS and is transmitted between corticothalamic, RT, and thalamocortical neurons by following the usual pathway [123-125]. In intact brains, the sleep oscillations are thus not seen in isolation, but are grouped by the cortically generated slow wave. The combination of the slow and spindle oscillations is especially visible during light sleep [59]. The same applies to the thalamic component of delta waves. As to the intracortical component of the delta wave, the frequency band of 1$4 \mathrm{~Hz}$ during SWS is partly determined by the shape of the depolarizing component of the slow oscillation ( 0.3 to $0.4 \mathrm{~s})$, that is, the K-complex. In humans, delta waves show periodic recurrence with the slow oscillation. That these two rhythms are distinct phenomena in human EEG is also evinced by the fact that delta declines from the first to the second NREM episode, whereas the slow oscillation does not [125]. In humans, stage 2 sleep shows a $0.8 \mathrm{~Hz}$ rhythm as well as a minor mode around $15 \mathrm{~Hz}$ (spindle waves).

5.2. Waking and REM Sleep. The major sensory and ventrolateral thalamic nuclei receive most of their brainstem innervation from the cholinergic mesopontine nuclei. In contrast, the associative and diffusely projecting thalamic nuclei mainly receive their ascending modulation from noncholinergic cells [126-128]. These pathways directly excite thalamocortical neurons and inhibit RT cells, with ensuing disinhibition of thalamocortical neurons and block of the sleep spindles. The cholinergic depolarization of thalamocortical cells presents a rapid nicotinic component and a slower sustained phase which is thought be largely caused by activation of metabotropic muscarinic ACh receptors (mAChRs; [129]). The overall effect is cortical arousal. Moreover, the effect on RT cells that leads to spindle block comprises an early short depolarization followed by a prolonged hyperpolarization, which is again probably caused by $\mathrm{mAChR}$ mediated stimulation of $\mathrm{K}^{+}$channels [130]. The ascending reticular arousal system also stimulates local circuit interneurons in thalamus, which may serve to enhance discriminatory tasks. A similar pattern is observed during REM sleep, in which however the brainstem drive on thalamus is supplemented by the one produced by the medulla reticular nuclei [131]. Cholinergic stimulus of the neocortex and several thalamic nuclear groups is also produced by the diffuse projections from basal forebrain cholinergic nuclei [132]. The fast oscillations of the active brain states are not limited to the cerebral cortex but also occur in thalamic neurons and are synchronized in corticothalamic networks [133].

The global effect is that the ascending arousal pathways depolarize the cortical and thalamic neurons, thus making them more ready to respond to sensory stimuli (during waking) or internal drives (during REM sleep). In depolarized neurons (around $-65 \mathrm{mV}$ ), the $I_{\mathrm{CaT}}$ is largely inactive and thus insensitive to excitatory input. In this condition, thalamic neurons reside in tonic firing (or transmission) mode [113]. A sensory or internal stimulus triggers a classic action potential which is then transferred to the cortical neurons. Therefore, signals are reliably passed on to the cortex, without producing the rhythmic bursts observed in NREM sleep. This pattern of cell activity is reflected in beta and gamma EEG waves, determined by short-range synchronization of neurons involved in neocortical, thalamic, or thalamocortical circuits $[53,54,134]$. The generalized depolarization also involves inhibitory interneurons, whose increased activity shapes the dynamics of the neural circuits implicated in specific functional tasks; a process sometimes called sculpturing inhibition [59].

The slow oscillation described in Section 5.1.4 also groups the beta/gamma oscillations typical of waking and REM. The fast $20-50 \mathrm{~Hz}$ rhythms appear on the depolarizing phase of the slow oscillation because these rapid oscillations are voltage dependent [59].

\section{The Main Features of Cholinergic Transmission in the Brain}

In cholinergic terminals, $\mathrm{ACh}$ is synthesized from choline and acetyl-CoA by choline acetyltransferase (ChAT; [135]). Reaction occurs in the cytoplasm, from which ACh is transported into synaptic vesicles by the vesicular ACh transporter (VAChT). ChAT and VAChT are also the main immunocytochemical markers of cholinergic neurons and fibers [136138]. They are regulated in a coordinated way, as the entire VAChT coding region is contained within the first ChAT intron, in chromosome $10[139,140]$. Once released, ACh can activate nAChRs as well as mAChRs. The transmitter is then degraded extracellularly into choline and acetic acid, by cholinesterase enzymes. In neural tissue, the main such enzyme is acetylcholinesterase (AChE), although other cholinesterases, such as butyrylcholinesterase, exist in different tissues [135]. Choline is then taken up by the cholinergic terminals through high-affinity, $\mathrm{Na}^{+}$-dependent, choline transporters (ChoT, with a $K_{m}$ for choline of about 1-5 $\mu \mathrm{M}$ ). These transporters have been cloned in 2000 ([141, 142], in which reference to earlier literature is found).

As discussed earlier, cholinergic fibers projecting from the mesopontine and basal forebrain nuclei profusely innervate the thalamus and cerebral cortex. ACh release cooperates with noradrenergic, histaminergic, and serotonergic transmission to increase the neocortical tone, sustain the awake state, and modulate synaptic plasticity $[61,143,144]$. ACh is also implicated in regulating the transitions between states with different level of vigilance [145, 146], included the switch between NREM and REM phases of sleep [59, 147].

The mechanisms by which ACh brings about its functions are rather intricate. Early work has tended to highlight the contribution of metabotropic mAChRs. In fact, the observed decrease in thalamic and neocortical neurons input resistance during wakefulness and REM sleep was originally attributed to a muscarinic-dependent $\mathrm{K}^{+}$channel inhibition 
$[50,144,148]$. However, in the last two decades it has been recognized that nAChRs also exert prominent regulatory roles in the brain (e.g., [146, 149-153]). The mechanisms are only partially understood, for several reasons. First, the full physiological meaning of the combinatorial complexity of nAChR subunits is unclear. Second, nAChRs are expressed at presynaptic, postsynaptic, and nonsynaptic locations [15, 154]. In classical cholinergic synapses, ACh reaches high concentrations (around $1 \mathrm{mM}$ ) in the synaptic cleft and is then degraded within milliseconds by AChE. This produces a strong and brief activation of postsynaptic nAChRs. Alternatively, diffuse release by varicose cholinergic fibers can sustain low tonic ACh levels in the cerebrospinal fluid. This pattern of release determines steady state regulation of ACh receptors and is thought to be particularly important in modulating presynaptic nAChRs that are known to control glutamate and GABA release in the cerebral cortex and thalamus. Such a tonic effect is possible because the acetylcholinesterase distribution in the brain does not precisely match that of ACh receptors. Hence, stable ACh concentrations up to approximately $1 \mu \mathrm{M}$ (but normally lower) can be detected in the extracellular compartment, even in the absence of cholinesterase inhibitors $[15,154,155]$. The balance of these phasic and tonic effects is uncertain because the ratio between the effects of synaptic and paracrine transmission is difficult to assess precisely, partly because of the difficulty of counting precisely the bona fide synaptic contacts [156]. Nonetheless, in the rat, macaque, and murine neocortices conspicuous cholinergic varicose fibers have been observed, with rare synaptic specializations [157-159]. A further complicating element is ACh receptor expression in glial cells [160]. Because very little is known about the contribution of this aspect to neocortical synaptic transmission, this issue will not be further discussed here. Finally, intrinsic cholinergic cells have been also observed in the neocortex of rodents. The precise function of these cells is unknown, but they are thought to be implicated in the regulation of pyramidal neuron excitability [161]. Differences have been observed between rats and mice in the timing of expression of these intrinsic neocortical cholinergic cells, which is slower in mice $[162,163]$. Hence, the maturation process of the nAChR-dependent control of principal cells in the neocortex may differ across mammals.

6.1. Physiological Roles of Heteromeric nAChRs in Neocortex and Thalamus. Heteromeric nAChRs are thought to give a major contribution to the steady state control of neocortical excitability, as they display high sensitivity to the agonists and slow desensitization. Consistent with this notion, the large majority of mutations known to be linked to ADNFLE and related pathologies map on genes coding for non- $\alpha 7 \mathrm{nAChR}$ subunits $[5,21,164,165]$. Hence, we summarize what is known about the physiology of heteromeric nAChRs in the frontal cortex and thalamus. Although a wide literature is available about nAChR subunit expression and pharmacology, which has been partly reviewed above, relatively scarce detailed electrophysiological evidence is available on brain slices of neocortex or thalamus. On this evidence, we focus the rest of the present section.
The nAChRs are implicated in both excitatory and inhibitory transmission in neocortex and thalamus. In both rats and mice, they control glutamate release from thalamocortical fibers in the frontal cortex [166-169], which accounts for the ACh role in arousal. Moreover, evidence is also available about nAChR expression in some populations of pyramidal cells, so that direct nicotinic regulation of principal cell excitability can also take place. In fact, somatic nicotinic currents have been measured in pyramidal neurons from rat neocortical layers II/III [170], layer V [171], and layer VI [172]. The evidence in mice is less univocal [173-175], although the overall ACh effect in layer $\mathrm{V}$ of the prefrontal cortex seems excitatory [175]. This is consistent with the global arousing role of $\mathrm{ACh}$, as cholinergic transmission in the deep layers of the prefrontal cortex can produce indirect effects on the general cortical tone. In fact, the prefrontal cortex is the only neocortical region that projects back to subcortical regions such as the basal cholinergic nuclei and the monoaminergic brainstem nuclei $[176,177]$. Because layer V constitutes the main subcortical output of neocortex, it also regulates cerebral regions implicated in motor control. Therefore it may have a special role in facilitating the hypermotor activity often observed in ADNFLE (see Section 8). Moreover layer $\mathrm{V}$ is thought to have a special role in seizure initiation and spread [178].

Current evidence suggests that the broad features of the nicotinic regulation of GABA release are similar across mammals. Expression of nAChRs on the soma of different interneuronal populations in the cerebral cortex is established in rats [179-181], humans [182], and mice [159, 174]. In general, nAChR activation tends to stimulate GABA release in different layers. Heteromeric nAChRs also exert presynaptic control of GABA release onto pyramidal cells [159, 183]. Moreover, indirect evidence suggests that nAChRs also regulate reciprocal interneuron inhibition, at least in layer $\mathrm{V}$ [159].

The thalamus is also a major target of ascending cholinergic innervation and it was shown that presynaptic heteromeric nAChRs stimulate GABA release in thalamic nuclei in avians $[184,185]$ and mouse [186], whereas scarce postsynaptic effect was observed on principal cells. The glutamatergic EPSCs measured in pyramidal cells of the lateral geniculate nucleus in chick are also stimulated by heteromeric nAChRs [185]. The contribution of different subunits $[185,187]$ as well as the balance between nicotinic and muscarinic effects are under investigation [188]. The general pattern, at least as far as the ventral lateral geniculate nucleus is concerned, seems broadly similar to what is observed in the frontal cortex. Nicotinic receptors stimulate both excitatory and inhibitory transmission, but the overall effect is probably excitatory [188]. Activation of GABAergic transmission is nonetheless fundamental to shape and regulate the excitatory response [186].

\section{GABAergic System: The Fundamentals}

GABAergic cells constitute a significant fraction of the brain neurons. Most of them are inhibitory interneurons, which account for $15-25 \%$ of the total neurons $[189,190]$, 
although the precise distribution in different regions and across different layers may vary [191]. In the cerebral cortex, local GABAergic interneurons tend to prevail, but it should be kept in mind that long-range intra- and interhemispheric GABAergic projections are also present in the neocortex of cats [192-195], rodents [193, 196-200], and primates [201]. These long-range GABAergic fibers probably exert global synchronizing functions that are potentially very important in epileptogenesis [202]. Moreover, specialized GABAergic nuclei are present in the brainstem. These, along with the thalamic RT nucleus, carry out important modulatory functions over the thalamocortical system, particularly during the the sleep-wake cycle, as has been discussed earlier $[59,61]$.

In GABAergic terminals, GABA is synthesized from Lglutamic acid by glutamic acid decarboxylase (GAD). Differently from the case of other neurotransmitters, two isoforms are known for this enzyme, GAD65 and GAD67, encoded by independently regulated genes. GAD65 is though to be more involved in synthesizing GABA in synaptic terminals, whereas GAD67 seems mainly responsible for synthesizing cytoplasmic GABA [203]. These enzymes are often used as GABAergic markers [204]. Synaptic vesicles are loaded with GABA by vesicular GABA transporters (VGAT); the first of which was cloned in 1997 [205, 206]. VGAT is molecularly distinct from the other neurotransmitter transporters. Being electrogenic, the transport mechanism is very sensitive to $V_{m}$. VGAT can also transport glycine (see [206] and references therein) and is expressed in glycinergic cells [207]. Hence, it is also named vesicular inhibitory amino acid transporter (VIAAT; [206]). However, current evidence suggests that other still unidentified inhibitory amino acid transporters exist in the CNS $[135,206]$. After GABA is released into the extracellular space, its action is mainly terminated by uptake into glia and neurons. At least four genes coding for GABA transporters (GATs) are known and at least three GAT proteins are expressed by glial cells and neurons (not necessarily GABAergic), along with a betaine transporter that is also able to reabsorb GABA [135]. Therefore GAT proteins are not used to label specific cell types. The reasons for this diversity are unclear. One reason may be related to transportermediated nonvesicular GABA release. Originally observed in retinal horizontal cells [208, 209], it was next identified in central neurons and astrocytes $[210,211]$. In brief, because many neurotransmitter transporters are electrogenic, changes in $V_{m}$ accompanied by appropriate extra- to intracellular ratios of the transported ions and transmitters may lead to the transporter extruding the neurotransmitter instead of absorbing it. The specific conditions under which this process occurs depend on the stoichiometry of the transporter. A full discussion is beyond the scope of the present paper and we refer the reader to several excellent reviews [212-215]. These and other evidence indicate that GABA is also synthesized and released by astrocytes and that GABA receptors are expressed in glial cells [216], although a full view of the physiological meaning of these observations is not available.

\section{Epilepsy and nAChRs: Autosomal Dominant Nocturnal Frontal Lobe Epilepsy}

ADNFLE $[217,218]$ is the first idiopathic epilepsy for which a monogenic cause was demonstrated [5]. ADNFLE is a partial epilepsy characterized by clusters of hyperkinetic seizures, mostly occurring during stage 2 of sleep [217]. Functional imaging studies show that attacks arise in specific foci in one of the frontal lobes, but the location of these foci is variable. The mean duration of seizures is around $30 \mathrm{~s}$. They usually begin in childhood and are sometimes misdiagnosed as nightmares or other parasomnias. No clear difference between males and females is observed. Sudden arousals are also typical of ADNFLE [218-222]. Cognitive and psychological alterations may accompany the epileptic phenotype and are probably more widespread than previously thought [223]. The clinical features of ADNFLE are very similar to those presented by the more common sporadic cases of nontraumatic nocturnal frontal lobe epilepsy [222, 224]. Therefore understanding the pathogenesis of ADNFLE should provide general information about the origin of sleep-related frontal epilepsy.

About $10-15 \%$ of the ADNFLE families characterized until now bear mutations on genes coding for nAChR subunits (Table 2). Until now, four ADNFLE-linked mutations have been identified on CHRNA4 (coding for the $\alpha 4$ subunit). All of these mutations are located on the M2 transmembrane domain [5, 225-228]. Five ADNFLE mutations have been found on CHRNB2 (coding for $\beta 2$ ). Two of them are located on M2 $[164,165,229]$, and three on M3 [230, 231]. Another mutation, linked to a related epileptic form, was identified on the M1 domain of CHRNA2 (coding for $\alpha 2$; [21]). Although the implication of CHRNA2 in ADNFLE seems very rare $[232,233]$, the above observation is interesting for comparison with the ADNFLE mutations and in that it suggests that $\alpha 2$ may also have significant roles in neocortical excitability. Figure 1 summarizes the approximate location of the different mutations. Penetrance can be as high as $80 \%$, and a broad range of onset time and severity has been observed even among members of the same family [234]. Considering the number of independent mutations on nicotinic subunits identified in families or individuals with affine epileptic forms, the aetiologic role of the cholinergic system in ADNFLE seems well established. Moreover, mutations on $\mathrm{nAChR}$ subunits have also been observed in sporadic NFLE forms (e.g., [235, 236]), which reinforces the notion that nAChRs are crucial regulators of excitability, particularly during sleep. However, the genes responsible for the majority of ADNFLE forms remain to be determined and evidence suggests the existence of at least two supplementary loci $[237,238]$. By now, the only ADNFLE-linked mutations identified outside the nicotinic subunit genes were found on the promoter of the corticotropin releasing hormone $(\mathrm{CRH})$ gene [238]. Although the physiological meaning of this observation is presently unclear, it is interesting to notice that several lines of evidence indicate that $\mathrm{CRH}$ modulates the cholinergic [239, 240] and noradrenergic pathways [241]. More details about the different ADNFLE mutations are given in Table 2 . 


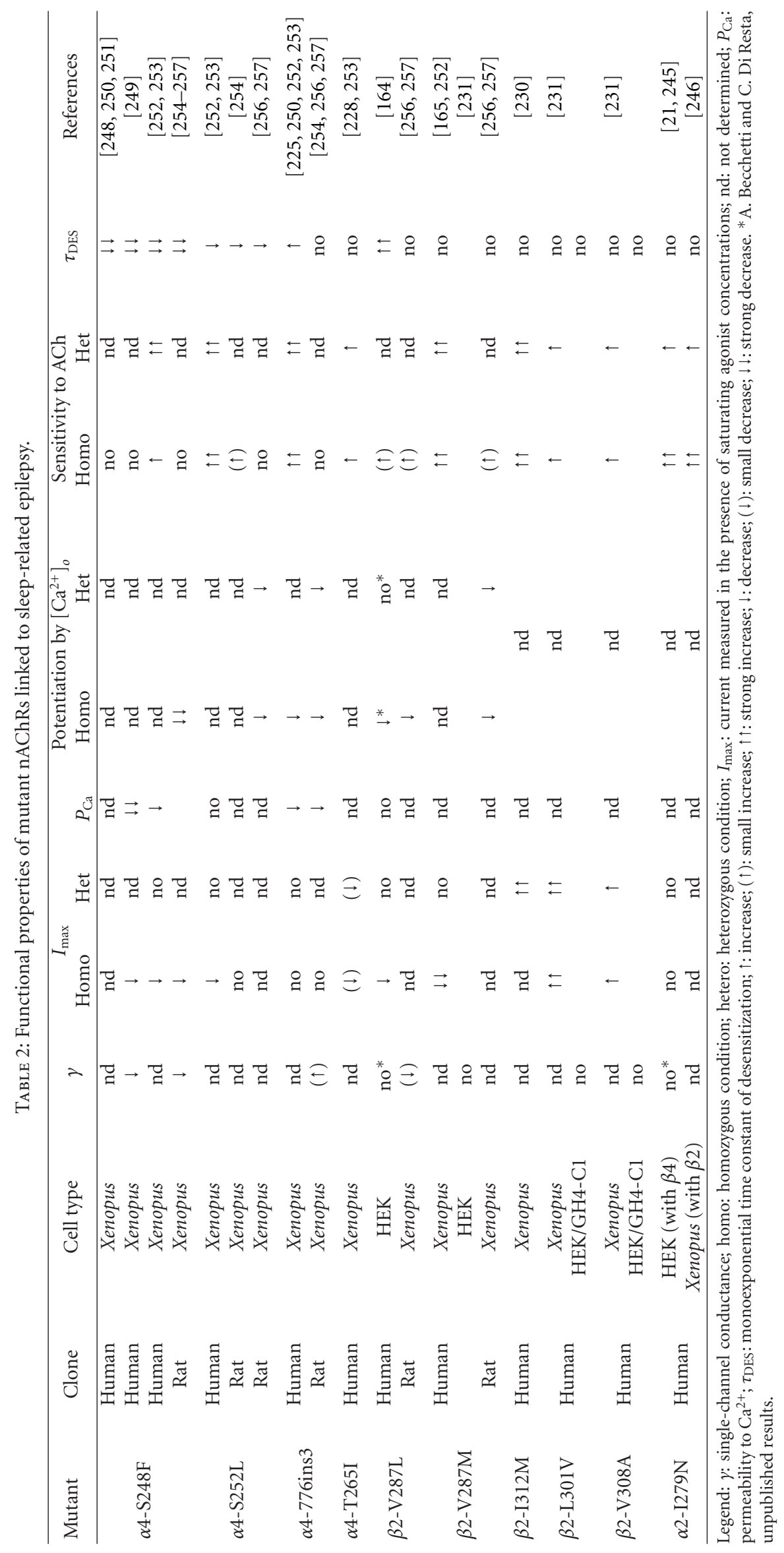


The frequent involvement of $\alpha 4$ and $\beta 2$ in ADNFLE is particularly suggestive of the importance of heteromeric nAChRs in regulating the sleep-waking cycle. The $\alpha 4 \beta 2$ receptors are very widespread in the mammalian brain, and $\beta 2$ is strongly upregulated during wakefulness and sleep deprivation [242]. Moreover, mice lacking $\beta 2$ present longer REM phases and a less frequent interruption of NREM sleep by microarousal events [243]. The symptoms of ADNFLE and the experimental evidence obtained in patients by studying with positron emission tomography the $\mathrm{AAChR}$ density throughout the brain [244] indicate that epileptogenesis may depend on hyperactivity of the cholinergic system that controls cortical arousal. However, many interpretation issues arise. First, one must explain why nAChR subunits widely expressed throughout the brain induce focal attacks in the frontal lobe. Second, it must be explained why seizures tend to occur during stage 2 sleep and are accompanied by frequent sudden arousals, which points to altered thalamocortical control. Third, the ictal manifestations can be partly considered as dishinibition of subcortical activity, which manifests itself as automatic motor and limbic activity [222]. Therefore, one must determine the connection between neocortex hyperexcitability and the specific subcortical effects. Moreover, as will be illustrated in the next section, the functional properties of different mutant receptors linked to ADNFLE are not identical. Hence, it is necessary to understand whether such molecular heterogeneity may partly explain the variability of cognitive and psychological symptoms observed by ADNFLE patients [222, 223].

\section{Ex Vivo Expression of Mutant Subunits Linked to ADNFLE}

The functional properties of ADNFLE mutations have been studied in Xenopus laevis oocytes and mammalian cell lines (mainly human embryonic kidney cells). By expressing the appropriate subunit combinations, the wild type (WT), mutant and heterozygous conditions were reproduced in vitro. These studies, summarized in Table 2, mostly focused on the $\alpha 4 \beta 2$ form. The exception is $\alpha 2-\mathrm{I} 279 \mathrm{~N}$, which was coexpressed with both $\beta 4[21,245]$ and $\beta 2$ [246], with broadly similar results.

Until now, no great alterations have been reported in transcription and membrane expression of mutant subunits [21, 245-257]. However, electrophysiological studies show that all the mutations located outside the pore region (M2) increase $\mathrm{nAChR}$ function in both homozygous and heterozygous conditions $[21,231,245,246]$. The overall effect comes down to a widening of the channel "window" current, that is, the crossover of the activation and desensitization curves. This is determined by a combination of higher sensitivity to the agonists and shift of the desensitization curve [231]. Considering the physiology of heteromeric nAChRs in the brain, it is likely that the main result of these changes is a significant potentiation of the steady state $\mathrm{nAChR}$ current in the presence of tonic ACh concentrations.

Mutations located in the M2 segment display a more complex behavior, as differences are frequently observed between the properties of the simulated homo- and heterozygotes obtained by expressing human $[164,165,225,228$, 238, 239, 248-253] and rat hortologue clones [254-257]. Homozygous channels often display a decrease in maximal current, sometimes accompanied by alteration of conductive properties. The strongest effect is observed in $\alpha 4-\mathrm{S} 248 \mathrm{~F}$, which presents a strong decrease in $\mathrm{Ca}^{2+}$ permeability and single-channel conductance, consistent with the position of this residue, close to the selectivity filter, and protruding into the conduction pathway [249]. These features had initially suggested a loss-of-function mechanism for ADNFLE, but more detailed studies in heterozygous condition in new $[164,165]$ as well as old mutations [251-253] indicated that an increase of nAChR function probably underlies the pathogenesis. The simplest hypothesis to explain the discrepancy between the homo- and the heterozygous condition is that, because M2 segments line the channel pore, when multiple homologous M2 amino acid substitutions are simultaneously present, a decrease in conductive properties are much more likely to appear. If the prevalent receptor forms are $(\alpha 4)_{2}(\beta 2)_{3}$ and $(\alpha 4)_{3}(\beta 2)_{2}[36,37]$, in homozygous condition $100 \%$ of the receptors contain either two or three mutant subunits. In heterozygotes, we can apply elementary combinatorial analysis [258] under the simplifying assumptions of equal expression and random association of the different subunits. In this case, irrespective of whether the mutant subunit is $\alpha 4$ or $\beta 2,18.75 \%$ of the channels would be WT, $18.75 \%$ would be mutant (i.e., containing a full complement of mutant subunits), $18.75 \%$ would contain one WT and two mutant subunits, and $43.75 \%$ would contain one mutant and two WT subunits. On the other hand, the latter percentage would be almost $47 \%$ had we assumed that the fifth subunit of the pentamer is more likely (with probability of 0.75 ) to be $\alpha$ than $\beta$, as it seems actually the case, based on available evidence [37]. This calculation refers to the case where the mutant subunit is $\beta 2$. Hence, in heterozygous condition, between 60 and $70 \%$ of the receptors contain only one or no mutant subunit. This percentage could be even higher in vivo, where other subunits, such as $\alpha 5$ [19], could associate to $\alpha 4 \beta 2$. Regardless of the underlying mechanism, experimental evidence shows that, in heterozygous condition, gating alterations appear, whose functional effects are broadly similar to those produced by the non-M2 mutations (Table 2).

Moreover, in the rat hortologues of human M2 mutations expressed in Xenopus oocytes, the $\mathrm{nAChR}$ regulation by extracellular calcium concentration $\left(\left[\mathrm{Ca}^{2+}\right]_{o}\right)$ is often altered $[256,257]$. The neuronal $\mathrm{nAChRs}$ are progressively potentiated by $\left[\mathrm{Ca}^{2+}\right]_{o}$, up to the physiological concentration of 1 to $2 \mathrm{mM}[259,260]$. Increasingly higher $\left[\mathrm{Ca}^{2+}\right]_{o}$ s produce increasing channel block [261]. The ensuing bell-shaped response to $\left[\mathrm{Ca}^{2+}\right]_{o}$ depends on $\mathrm{Ca}^{2+}$ binding to several metal binding sites, located within the $\mathrm{N}$-terminal domain. These sites contain typical EF-like helix-loop-helix motifs, with conserved terminal glutamate residues, whose neutralization decreases or completely inhibits the regulation by $\left[\mathrm{Ca}^{2+}\right]_{o}$ [262]. In the above mutant $\alpha 4 \beta 2 \mathrm{nAChRs}$, the potentiating effect of $\left[\mathrm{Ca}^{2+}\right]_{o}$ between 0 and $2 \mathrm{mM}$ was found to be strongly reduced [256]. The effect is attributed to altered allosteric activation [257]. Although these effects have been 
yet not fully studied in the human clones and the evidence in heterozygotes is incomplete, the decreased sensitivity to $\left[\mathrm{Ca}^{2+}\right]_{o}$ may once again turn out to amount to increased receptor function [257]. The two proposed mechanisms are as follow: (a) lower nAChR-dependent GABA release, with ensuing circuit dishinibition; (b) increased glutamate release during bouts of synchronous activity in the neocortex [256, 257].

Overall, evidence in expression systems tends to favor an epileptogenic mechanisms caused by potentiation of neocortical heteromeric nAChR function, which would be consistent with the observation that deleting either $\alpha 4$ or $\beta 2$ in murine strains does not lead to seizure facilitation or other aspects of the ADNFLE symptoms [263, 264]. However, a note of caution should be added. Considering that nAChRs have complex pre- and postsynaptic roles in the brain and that long-term exposure to agonists modulates the $\alpha 4 \beta 2$ receptor expression $[35,265-267]$, it would be unsafe to rule out the possibility that similar pathological effects are produced by different mechanisms, especially in families or individuals with different genetic backgrounds.

\section{Animal Models of ADNFLE}

The above studies leave us with the problem of understanding (1) whether the nAChR alterations observed in vitro reproduce the physiological situation; (2) how hyperfunctional nAChRs can lead to ADNFLE; (3) whether and in which conditions hypofunctional channels can produce similar effects. Several animal models were recently generated to address these issues. Not surprisingly, no mutant strain perfectly reproduces the human pathology. However, they mimic several features of ANDFLE in that they often induce alterations in arousal and sleep physiology that may be accompanied by spontaneous seizures or decreased threshold to seizure development. Initially, knock-in murine strains were produced which express mutations that, although not found in ADNFLE families, confer to the receptor the hypersensitivity that is often observed The updated reference in ADNFLE mutations. In particular, hypersensitive $\alpha 4 \beta 2$ nAChRs were obtained by using $\alpha 4$ subunits carrying amino acid substitutions in the L9' position of M2 (corresponding to L251 of the human clone). Substitution with Ser produces much decreased concentration threshold for nicotineinduced seizures $[268,269]$, although the overall phenotype is probably too severe to faithfully represent the ADNFLE features, with frequent lethality in homozygous condition. A milder phenotype is observed when L9' is substituted with Ala [270, 271]. These strains do not show spontaneous seizures. However, they present at 5 -fold decrease of the nicotine dose necessary to induced seizures and more fragmented NREM sleep. Moreover, the seizures in mutants present features more analogous to those observed in ADNFLE, with hyperkinetic movements and asymmetrical posturing [271].

The first heterozygous ADNFLE murine models were produced on C57BL/6J genetic background expressing either $\alpha 4-\mathrm{S} 252 \mathrm{~F}$ or $\alpha 4-+\mathrm{L} 264$, respectively, homologous to the human mutant subunits $\alpha 4-\mathrm{S} 248 \mathrm{~F}$ and $\alpha 4$-(776ins3) [183]. These mice show recurrent seizures accompanied, at the cellular level, by potentiation of the nicotine-induced GABA release in layer II/III of the prefrontal cortex. Seizures do not seem to be entrained to the sleep-wake cycle. Overall, these strains may represent a severe model of ADNFLE, as human patients present a spectrum of clinical manifestations and only about one-third display clear epileptiform EEG during the crises [220]. Perhaps not surprisingly, the effects of these mutations are strain dependent. A second murine model expressing $\alpha 4-\mathrm{S} 248 \mathrm{~F}$ was generated on a mixed CD1-129/Sv background. This strain displayed a milder phenotype, with nicotine-induced dystonic arousal complex similar to the motor features of human ADNFLE, but not spontaneous epileptiform EEG alteration [264].

Zhu et al. [272] recently generated transgenic rats expressing $\alpha 4-S 284 \mathrm{~L}$, corresponding to S252L of the human sequence. These rats showed a spectrum of seizure phenotypes during SWS similar to those observed in humans. This extension of the studied mammalian species is welcome because, although the treatments that lead to epileptiform insurgence in rodent brain slices are similar to those effective in human tissue samples [273], the morphological and neurophysiological differences between rats and mice make these models complementary [273, 274]. From a neurophysiological point of view, mutant rats exhibited attenuation of synaptic and extrasynaptic GABAergic transmission and abnormal glutamate release during SWS. A knock-in model for $\beta 2-\mathrm{V} 287 \mathrm{~L}$ was also recently made available by $\mathrm{Xu}$ and colleagues [275]. Once again, mice display a clearly disturbed sleep pattern, with significant increase in activity during the light period (corresponding to the rest period, in mice). Animals also show increased anxiety-related behaviour, but no overt seizure phenotype. No neurophysiological data are yet available on this strain.

In general, the above knock-in models show little overt morphological changes in the brain, in agreement with what is observed in ADNFLE patients. Moreover, the observed phenotypes confirm the notion that the arousal system and the sleep-waking cycle are very sensitive to alterations of heteromeric nAChR-mediated transmission. Nonetheless, the phenotype differences between strains make the implications for epileptogenesis not straightforward. The neurophysiological characterization, incomplete as it may be, indicates that the presence of ADNFLE mutations alters neurotransmitter release in the frontal cortex, especially GABA. This is in line with the known roles of heteromeric nAChRs in the modulation of neurotransmitter release in the frontal cortex and thus encourages deeper physiological studies in these animals, giving perhaps more attention to the thalamocortical interplay, which has been so far scarcely attended to.

As in other epileptic forms, the next generation of murine strains will need to address more specific questions related to the mechanisms of seizures and their developmental origin, by attempting the production of targeted or conditional expression of the mutant subunits [274]. One such attempt has been conducted by Manfredi and colleagues [276], who developed ADNFLE murine strains conditionally expressing the $\beta 2-\mathrm{V} 287 \mathrm{~L}$ subunit, in a doxycycline-dependent way ("TET-off" system; [277]). Expression of $\beta 2-V 287 \mathrm{~L}$ produces a spontaneous epileptic phenotype, whose penetrance 
and severity depend on gene dosage. Seizures generally occur during periods of increased delta wave activity, mostly during the light period, which corresponds to the resting-sleeping phase, in mouse. Interestingly, silencing the transgene expression in adult age did not revert the epileptic phenotype [276]. This suggests that the epileptogenic action of $\beta 2-$ V287L could take place during brain development. In fact, silencing the mutant gene with doxycycline between embryonic day 1 (E1) and postnatal day 15 (P15) produces a phenotype identical to the WT. When treatment is interrupted, rapid reexpression of the mutant subunit is observed, but no evidence of seizures [276]. Therefore, to induce the epileptic phenotype, $\beta 2$-V287L needs to be expressed during sensitive phases of brain development [see Section 11.2], suggesting that critical stages of synaptic stabilization are implicated in ADNFLE.

\section{Implication of Mutant $n A C h R s$ in the Pathogenesis of ADNFLE}

As has been observed earlier, the clinical aspects as well as the molecular and neurophysiological features of ADNFLE present some heterogeneity. It has in fact been recently observed that it is difficult to explain all the aspects of nocturnal frontal lobe epilepsy with an all-encompassing theory [278]. Some general points can however be made. The appearance of crises almost exclusively during NREM sleep and the generally disturbed sleep in murine models of ADNFLE can be probably attributed to excess of the normal arousal effect of the cholinergic system, which normally controls the transition to both waking and REM stages (see Section 5.2). The fact that the hypermotor seizures are often observed in nocturnal frontal lobe epilepsy is a symptom of subcortical dishinibition $[222,278]$. This may be reconciled with the notion that the frontal cortex layer $\mathrm{V}$ is the main output to subcortical structures and is also the region more ready to develop epileptiform activity. It should be also added that the local GABAergic innervation is particularly dense in layer $\mathrm{V}$ [279], which should make this structure particularly sensitive to the frequently observed alteration of GABAergic transmission in murine models of ADNFLE. Another hypothesis about the mechanism by which altered nAChRs can lead to hyperkinetic activity turns on the fact that dopamine release in the striatum is regulated by nAChRs [280]. In fact, in a cohort of ADNFLE patients, reduced mesostriatal dopamine receptor (D1) expression was observed [281].

11.1. Specific Epileptogenic Mechanisms in Mature Circuits. What is known about the nAChR function in the neocortex as well as the results obtained with the available rodent strains suggest the following possible causes of hyperexcitability; some of which are not mutually exclusive.

(i) Postinhibitory Hyperexcitability. Hyperfunctional nAChRs may cause excessive GABA release. The ensuing hyperpolarization of pyramidal neurons would deinactivate lowthreshold $I_{\text {CaT }}$ and activate $I_{H}$ currents, thus making cells more sensitive to postinhibitory rebound $[6,183]$. (ii) Local Circuit Dishinibition. Neurophysiological evidence shows that reciprocal inhibition between fast-spiking interneurons (mainly basket cells) is operant in the rodents' neocortex [282-284]. Hyperfunctional heteromeric nAChRs could thus potentiate GABA release on interneurons, as recent evidence indicates that reciprocal GABAergic transmission between basket cells can be regulated by heteromeric nAChRs [159]. This process would be more probable during SWS, when excitatory thalamocortical neurons tend to be inhibited [101]. In this state, an upsurge of ACh in the neocortex may shift the balance of the basket cells' network towards reciprocal inhibition, thus facilitating seizure development before the parallel ACh release in the thalamus stimulates the thalamocortical drive. This mechanism did not appear to be operant in Klaassen's mice [183], but it could explain Zhu's [272] results.

(iii) Increased Glutamatergic Drive from Thalamocortical Fibers. An alternative hypothesis is that, although during stage 2 of NREM sleep the cholinergic tone is generally low, hyperfunctional $\mathrm{nAChRs}$ could maintain abnormally high glutamate release, even in the face of low ACh levels. The data obtained in knock-in rats indicate that increased nicotinedependent glutamate release is indeed present in mutant strains during SWS [272]. However, the possible balance of the effects of mechanisms (ii) and (iii) is difficult to predict, since thalamocortical fibers innervate pyramidal as well as interneurons. Hence, I believe this is a valuable issue for further experimental work, as it could reveal subtle aspects of neocortical transmission.

(iv) The Contribution of Thalamus: Promotion of Sleep Spindles. As discussed above, stage 2 of sleep is characterized by sleep spindles. These are generated in the thalamus by the inhibitory action of RT cells onto thalamocortical neurons, but the activity of cortical neurons is essential to synchronize the spindle appearance across wide regions. Sleep spindles are liable to turn into epileptiform activity [50] and could be promoted by nAChR-dependent stimulation of glutamate release onto RT neurons, with ensuing increased release of GABA onto thalamocortical cells [285]. This is another mechanism for which very little experimental work is available.

11.2. Possible Developmental Role of nAChRs in Epileptogenesis. Understanding how neuronal circuits alteration during development can facilitate the later establishment of a full-blown epileptic disease is a central problem in epileptology, with many practical implications. Besides leading to better understanding of the natural history of epilepsy, a deeper grasp of this issue will probably lead to much better comprehension of the mechanisms underlying intractable epilepsy [286]. This may depend on stable anatomical or physiological circuit alterations that make the overall network activity difficult to control with the available antiepileptic drugs (AEDs). The results obtained with mice conditionally expressing $\beta 2$-V287L suggest that, in the specific case of ADFNLE, altered nicotinic regulation of brain circuit 
maturation may contribute to the pathogenesis [276]. Because no evident neuroanatomical alterations are observed in either patients or animal models of ADNFLE [183, 222, $244,264,272,275,276]$ the developmental effects must involve subtle changes in the proper synaptic balance that are established during network maturation.

A hallmark of mammalian brain development is the typical "brain growth spurt" occurring around birth. This phase is particularly prolonged in humans, where it begins during the last trimester of pregnancy and continues throughout the first 2 years of life. In mice and rats, the quick brain growth spans the first month of postnatal life, during which extensive neurite extension is followed by establishment of neural connections and synaptogenesis. Myelinization and circuit refinement through cell and synaptic death complete the functional network stabilization [287, 288]. This stage is accompanied by maturation of the cholinergic system and presents an upsurge in $\mathrm{nAChR}$ subunit expression, which precedes full maturation of the cortical cholinergic fiber network and expression of muscarinic receptors (reviewed in [288]). In particular, expression of $\alpha 4$ and $\beta 2$ subunits reaches a peak towards the end of the second postnatal week $[289,290]$. During this period, the density of extrinsic cholinergic innervation $[162,291]$ increases dramatically in rats. The overall timing seems to be similar in the mouse $[159,163]$, although data are less extensive. Maturation of the cholinergic system regulates brain maturation, as treatment with various cholinergic ligands (including nicotine) around age $\mathrm{P} 10$ produces persistent behavioral and morphological alterations [287]. Moreover, mice that lack $\beta 2$ show regionspecific changes in cortical structure [292]. In general, ample evidence that cannot be fully reviewed here shows that the early action of the cholinergic system is important for proper structural and cognitive development [289]. The specific mechanisms by which nAChRs regulate neural circuit wiring in the frontal cortex are only beginning to be elucidated. Importantly, the spontaneous $\mathrm{nAChR}$ activity was found to control the switch between the excitatory and inhibitory roles of GABA during development [293]. The progressive substitution of the plasma membrane transporter NKCC1 with KCC2, which is at the basis of this process ([38, 294, 295]), is under control of both homo- and heteromeric nAChR activity [293]. KCC2 appears in different layers at somewhat different stages (after age P3 in layer V pyramidal cells) and its expression is concomitant with the formation of GABAergic synapses [296]. Precise timing of early GABAergic excitation is important for early neuronal development and proper integration of cells into circuits $[38,297]$. Therefore, overly active nAChRs in ADNFLE could alter proper timing of this process, with ensuing long-term alteration of neocortical microcircuit architecture and the excitatory to inhibitory balance.

\section{Pharmacological Aspects}

Control of ADNFLE symptoms is often obtained with carbamazepine [218, 298]. Recent evidence, although still limited, indicates that good results can also be obtained in NFLE patients with topiramate [299] and oxcarbazepine (including in some children refractory to carbamazepine, [300, 301]). Oxcarbazepine is a less toxic analog of carbamazepine, which is rapidly metabolized to 10,11-dihydro-10-hydroxycarbamazepine (MHD), the clinically effective compound [302-304]. Nonetheless, as is often the case in epilepsy, about $30 \%$ of the patients are refractory to pharmacologic treatment [220]. What is worse, in the case of ADNFLE (and NFLE in general), extreme caution must be exerted in attempting surgical therapy, considering the widespread distribution of the mutant receptors in the brain and the current uncertainties about the precise pathogenic mechanisms [222]. Therefore, more thorough pharmacological studies seem particularly urgent for these diseases.

Most AEDs exert their action by targeting ion channels. By far the best characterized effects concern AED modulation of voltage-gated $\mathrm{Na}^{+}$channels [305]. In these, carbamazepine retards the recovery from channel inactivation $[306,307]$. Oxcarbazepine and MHD, although less well characterized, are thought to produce similar effects $[305,308]$. Topiramate also produces a spectrum of inhibitory actions on voltagegated $\mathrm{Na}^{+}$channels $[309,310]$. However, growing evidence indicates that the action of many common AEDs is far from being specific. Importantly, from our standpoint, several AEDs have been found to modulate ligand-gated channels. In particular, $\alpha 4 \beta 2 \mathrm{nAChRs}$ are blocked by carbamazepine [311], oxcarbazepine/MHD [245], and lamotrigine [312]. The principal mechanism is probably block of the open channel [311]. The altered pharmacological properties observed in many ADNFLE mutations thus suggested that mutant nAChRs may also respond differently to AEDs. In fact, ADNFLE mutations tend to increase the $\alpha 4 \beta 2 \mathrm{nAChR}$ sensitivity to AEDs [245, 253,311], although the opposite effect was observed with $\alpha 2 \beta 2$ [246]. These observations could partly explain the particular efficacy of carbamazepinerelated drugs on ADNFLE. Irrespective of their possible clinical significance, which is presently uncertain, these results certainly suggest possible medicinal chemistry strategies aimed at producing new generation compounds with different potency on $\mathrm{Na}^{+}$and ligand-gated channels, for attempting more selective ion channel targeting for therapeutic applications. These compounds could be also tested during brain circuit development, to specifically modulate the relevant ion channels during the sensitive stages of neuronal connection establishment and refinement.

\section{Abbreviations}

ACh: Acetylcholine

AChE: Acetylcholinesterase

ADNFLE: Autosomal dominant nocturnal frontal lobe epilepsy

AED: $\quad$ Antiepileptic drug

CAE: Childhood absence epilepsy

ChAT: Choline acetyltransferase

CNS: Central nervous system

ChoT: Choline transporter

CoA: $\quad$ Coenzyme A

CRH: Corticotrophin-releasing hormone

DS: $\quad$ Dravet syndrome 
$\mathrm{EC}_{50}$ : Half-effective concentration

EEG: Electroencephalography

EPSP: Excitatory postsynaptic potential

FS: $\quad$ Febrile seizures

GABA: $\quad \gamma$-amino butyric acid

GAD: Glutamic acid decarboxylase

GAT: GABA transporter

GEFS+: Generalized epilepsy with febrile seizures plus

5- $\mathrm{HT}_{3}$ : 5-Hydroxytryptamine

$I_{\mathrm{CaT}}: \quad$ T-type calcium currents

$I_{\mathrm{H}}$ : Hyperpolarization-activated currents

IPSP: Inhibitory postsynaptic potential

JME: Juvenile myoclonic epilepsy

KCC: $\quad \mathrm{K}^{+}-\mathrm{Cl}^{-}$cotransporter

mAChR: Muscarinic acetylcholine receptor

MHD: 10,11-Dihydro-10-hydroxycarbamazepine

nAChR: Neuronal nicotinic acetylcholine receptor

NKCC: $\mathrm{Na}^{+}-\mathrm{K}^{+}-\mathrm{Cl}^{-}$cotransporter

NFLE: Nocturnal frontal lobe epilepsy

NREM: Non-REM

REM: $\quad$ Rapid eye movements

RT: Reticular thalamic nucleus

SWS: Slow wave sleep

VAChT: Vesicular acetylcholine transporter

VGAT: Vesicular GABA transporter

VIAAT: Vesicular inhibitory amino acid transporter

WT: $\quad$ Wild type.

\section{Conflict of Interests}

The author declares that he has no commercial or financial relationship that could be construed as a conflict of interests.

\section{Acknowledgments}

The author's work is currently funded by Telethon, Italy, (Grant no. GGP12147) and the University of Milano Bicocca (Fondo d'Ateneo per la Ricerca, FAR 2009-2011).

\section{References}

[1] C. A. R. Boyd and D. Noble, Eds., Logic of Life. the Challenge of Integrative Physiology, Oxford University Press, New York, NY, USA, 1993.

[2] O. K. Steinlein, "Genetic mechanisms that underlie epilepsy," Nature Reviews Neuroscience, vol. 5, no. 5, pp. 400-408, 2004.

[3] D. M. Kullmann and S. G. Waxman, "Neurological channelopathies: new insights into disease mechanisms and ion channel function," Journal of Physiology, vol. 588, no. 11, pp. 1823-1827, 2010.

[4] R. Dingledine, "Glutamatergic mechanisms related to epilepsy," in Jasper's Basic Mechanisms of the Epilepsies, J. L. Noebels, M. Avoli, M. A. Rogawski, R. W. Olsen, and A. V. Delgado-Escueta, Eds., pp. 122-131, Oxford University Press, New York, NY, USA, 4th edition, 2012.

[5] O. K. Steinlein, J. C. Mulley, P. Propping et al., "A missense mutation in the neuronal nicotinic acetylcholine receptor $\alpha 4$ subunit is associated with autosomal dominant nocturnal frontal lobe epilepsy," Nature Genetics, vol. 11, no. 2, pp. 201203, 1995.

[6] E. O. Mann and I. Mody, "The multifaceted role of inhibition in epilepsy: seizure-genesis through excessive GABAergic inhibition in autosomal dominant nocturnal frontal lobe epilepsy," Current Opinion in Neurology, vol. 21, no. 2, pp. 155-160, 2008.

[7] P. S. Miller and T. G. Smart, "Binding, activation and modulation of Cys-loop receptors," Trends in Pharmacological Sciences, vol. 31, no. 4, pp. 161-174, 2010.

[8] A. J. Thompson, H. A. Lester, and S. C. R. Lummis, "The structural basis of function in Cys-loop receptors," Quarterly Reviews of Biophysics, vol. 43, no. 4, pp. 449-499, 2010.

[9] I. Wessler and C. J. Kirkpatrick, "Acetylcholine beyond neurons: the non-neuronal cholinergic system in humans," British Journal of Pharmacology, vol. 154, no. 8, pp. 1558-1571, 2008.

[10] S. Z. Young and A. Bordey, "GABA's control of stem and cancer cell proliferation in adult neural and peripheral niches," Physiology, vol. 24, no. 3, pp. 171-185, 2009.

[11] P. Ambrosi and A. Becchetti, "Targeting neuronal nicotinic receptors in cancer: new ligands and potential side-effects," Recent Patents on Anti-Cancer Drug Discovery, vol. 8, no. 1, pp. 38-52, 2013.

[12] E. X. Albuquerque, E. F. R. Pereira, M. Alkondon, and S. W. Rogers, "Mammalian nicotinic acetylcholine receptors: from structure to function," Physiological Reviews, vol. 89, no. 1, pp. 73-120, 2009.

[13] J. Lindstrom, "Purification and cloning of nicotinic acetylcholine receptors," in Neuronal Nicotinic Receptors. Pharmacology and Therapeutic Opportunities, S. P. Arneric and J. D. Brioni, Eds., pp. 3-24, John Wiley and Sons, New York, NY, USA, 1999.

[14] A. Karlin, "Emerging structure of the nicotinic acetylcholine receptors," Nature Reviews Neuroscience, vol. 3, no. 2, pp. 102-114, 2002.

[15] J. A. Dani and D. Bertrand, "Nicotinic acetylcholine receptors and nicotinic cholinergic mechanisms of the central nervous system," Annual Review of Pharmacology and Toxicology, vol. 47, pp. 699-729, 2007.

[16] S. S. Khiroug, P. C. Harkness, P. W. Lamb et al., "Rat nicotinic ACh receptor $\alpha 7$ and $\beta 2$ subunits co-assemble to form functional heteromeric nicotinic receptor channels," Journal of Physiology, vol. 540, no. 2, pp. 425-434, 2002.

[17] T. A. Murray, D. Bertrand, R. L. Papke et al., “ $\alpha 7 \beta 2$ nicotinic acetylcholine receptors assemble, function, and are activated primarily via their $\alpha 7-\alpha 7$ interfaces," Molecular Pharmacology, vol. 81, no. 2, pp. 175-188, 2012.

[18] C. Gotti, M. Zoli, and F. Clementi, "Brain nicotinic acetylcholine receptors: native subtypes and their relevance," Trends in Pharmacological Sciences, vol. 27, no. 9, pp. 482491, 2006.

[19] J. Ramirez-Latorre, C. R. Yu, X. Qu, F. Perin, A. Karlin, and L. Role, "Functional contributions of $\alpha 5$ subunit to neuronal acetylcholine receptor channels," Nature, vol. 380, no. 6572, pp. 347-351, 1996.

[20] Z. Y. Han, N. Le Novère, M. Zoli, J. A. Hill, N. Champtiaux, and J. P. Changeux, "Localization of nAChR subunit mRNAs in the brain of Macaca mulatta," European Journal of Neuroscience, vol. 12, no. 10, pp. 3664-3674, 2000.

[21] P. Aridon, C. Marini, C. D. Resta et al., "Increased sensitivity of the neuronal nicotinic receptor $\alpha 2$ subunit causes familial epilepsy with nocturnal wandering and ictal fear," American Journal of Human Genetics, vol. 79, no. 2, pp. 342-350, 2006. 
[22] K. Ishii, J. K. Wong, and K. Sumikawa, "Comparison of $\alpha 2$ nicotinic acetylcholine receptor subunit mRNA expression in the central nervous system of rats and mice," Journal of Comparative Neurology, vol. 493, no. 2, pp. 241-260, 2005.

[23] M. Quik, Y. Polonskaya, A. Gillespie, M. Jakowec, G. K. Lloyd, and J. W. Langston, "Localization of nicotinic receptor subunit mRNAs in monkey brain by in situ hybridization," Journal of Comparative Neurology, vol. 425, no. 1, pp. 58-69, 2000.

[24] L. C. Gahring, K. Persiyanov, and S. W. Rogers, "Neuronal and astrocyte expression of nicotinic receptor subunit $\beta 4$ in the adult mouse brain," Journal of Comparative Neurology, vol. 468, no. 3, pp. 322-333, 2004.

[25] E. Hellström-Lindahl, O. Gorbounova, A. Seiger, M. Mousavi, and A. Nordberg, "Regional distribution of nicotinic receptors during prenatal development of human brain and spinal cord," Developmental Brain Research, vol. 108, no. 1-2, pp. 147-160, 1998.

[26] C. Gotti, F. Clementi, A. Fornari et al., "Structural and functional diversity of native brain neuronal nicotinic receptors," Biochemical Pharmacology, vol. 78, no. 7, pp. 703-711, 2009.

[27] N. Unwin, "Refined structure of the nicotinic acetylcholine receptor at $4 \AA$ resolution," Journal of Molecular Biology, vol. 346, no. 4, pp. 967-989, 2005.

[28] A. Miyazawa, Y. Fujiyoshi, and N. Unwin, "Structure and gating mechanism of the acetylcholine receptor pore," Nature, vol. 423, no. 6943, pp. 949-955, 2003.

[29] S. J. Moss, B. J. McDonald, Y. Rudhard, and R. Schoepfer, "Phosphorylation of the predicted major intracellular domains of the rat and chick neuronal nicotinic acetylcholine receptor $\alpha 7$ subunit by cAMP-dependent protein kinase," Neuropharmacology, vol. 35, no. 8, pp. 1023-1028, 1996.

[30] L. Wecker, X. Guo, A. M. Rycerz, and S. C. Edwards, "Cyclic AMP-dependent protein kinase (PKA) and protein kinase $\mathrm{C}$ phosphorylate sites in the amino acid sequence corresponding to the M3/M4 cytoplasmic domain of $\alpha 4$ neuronal nicotinic receptor subunits," Journal of Neurochemistry, vol. 76, no. 3, pp. 711-720, 2001.

[31] V. Tsetlin, D. Kuzmin, and I. Kasheverov, "Assembly of nicotinic and other Cys-loop receptors," Journal of Neurochemistry, vol. 116, no. 5, pp. 734-741, 2011.

[32] O. S. Andersen and R. E. Koeppe, "Molecular determinants of channel function," Physiological Reviews, vol. 72, supplement 4, pp. S89-S158, 1992.

[33] S. Fucile, " $\mathrm{Ca}^{2+}$ permeability of nicotinic acetylcholine receptors," Cell Calcium, vol. 35, no. 1, pp. 1-8, 2004.

[34] P. J. O. Covernton and J. G. Connolly, "Multiple components in the agonist concentration-response relationships of neuronal nicotinic acetylcholine receptors," Journal of Neuroscience Methods, vol. 96, no. 1, pp. 63-70, 2000.

[35] B. Buisson and D. Bertrand, "Chronic exposure to nicotine upregulates the human $\alpha 4 \beta 2$ nicotinic acetylcholine receptor function," Journal of Neuroscience, vol. 21, no. 6, pp. 18191829, 2001.

[36] M. E. Nelson, A. Kuryatov, C. H. Choi, Y. Zhou, and J. Lindstrom, "Alternate stoichiometries of $\alpha 4 \beta 2$ nicotinic acetylcholine receptors," Molecular Pharmacology, vol. 63, no. 2, pp. 332-341, 2003.

[37] Y. Zhou, M. E. Nelson, A. Kuryatov, C. Choi, J. Cooper, and J. Lindstrom, "Human $\alpha 4 / \beta 2$ acetylcholine receptors formed from linked subunits," Journal of Neuroscience, vol. 23, no. 27, pp. 9004-9015, 2003.

[38] Y. Ben-Ari, J. L. Gaiarsa, R. Tyzio, and R. Khazipov, "GABA: a pioneer transmitter that excites immature neurons and generates primitive oscillations," Physiological Reviews, vol. 87, no. 4, pp. 1215-1284, 2007.
[39] W. Sieghart and G. Sperk, "Subunit composition, distribution and function of GABA(A) receptor subtypes," Current Topics in Medicinal Chemistry, vol. 2, no. 8, pp. 795-816, 2002.

[40] P. Cossette, P. Lachance-Touchette, and G. A. Rouleau, "Mutated GABAA receptor subunits in idiopathic generalized epilepsy," in Jasper's Basic Mechanisms of the Epilepsies, J. L. Noebels, M. Avoli, M. A. Rogawski, R. W. Olsen, and A. V. Delgado-Escueta, Eds., pp. 122-131, Oxford University Press, New York, NY, USA, 4th edition, 2012.

[41] K. Fatima-Shad and P. H. Barry, "Anion permeation in GABA- and glycine-gated channels of mammalian cultured hippocampal neurons," Proceedings of the Royal Society B, vol. 253, no. 1336, pp. 69-75, 1993.

[42] K. Baer, H. J. Waldvogel, R. L. Faull, and M. I. Rees, "Localization og glycine receptors in the human forebrain, brainstem, and cervical spinal cord: an immunohistochemical review," Frontiers in Molecular Neuroscience, vol. 2, article 25, 2009.

[43] A. Triller, F. Cluzeaud, and H. Korn, "Gamma-aminobutyric acid-containing terminals can be apposed to glycine receptors at central synapses," Journal of Cell Biology, vol. 104, no. 4, pp. 947-956, 1987.

[44] P. Jonas, J. Bischofberger, and J. Sandkühler, "Corelease of two fast neurotransmitters at a central synapse," Science, vol. 281, no. 5375, pp. 419-424, 1998.

[45] R. W. Olsen, H. J. Hanchar, P. Meera, and M. Wallner, "GABAA receptor subtypes: the "one glass of wine" receptors," Alcohol, vol. 41, no. 3, pp. 201-209, 2007.

[46] M. Wang, "Neurosteroids and GABA-A receptor function," Frontiers in Endocrinology, vol. 2, article 44, 2012.

[47] A. Marty and I. Llano, "Excitatory effects of GABA in established brain networks," Trends in Neurosciences, vol. 28, no. 6, pp. 284-289, 2005.

[48] R. Macdonald, J. Q. Kang, and M. J. Gallagher, "GABAA receptor mutations and genetic epilepsies," in Jasper's Basic Mechanisms of the Epilepsies, J. L. Noebels, M. Avoli, M. A. Rogawski, R. W. Olsen, and A. V. Delgado-Escueta, Eds., pp. 740-749, Oxford University Press, New York, NY, USA, 4th edition, 2012.

[49] J. Siegel, The Neural Control of Sleep and Waking, Springer, New York, NY, USA, 2002.

[50] M. Steriade, Neuronal Substrates of Sleep and Epilepsy, Cambridge University Press, Cambridge, UK, 2003.

[51] W. Singer, "Synchronization of cortical activity and its putative role in information processing and learning," Annual Review of Physiology, vol. 55, pp. 349-374, 1993.

[52] M. H. J. Munk, P. R. Roelfsema, P. König, A. K. Engel, and W. Singer, "Role of reticular activation in the modulation of intracortical synchronization," Science, vol. 272, no. 5259, pp. 271-274, 1996.

[53] M. Steriade, F. Amzica, and D. Contreras, "Synchronization of fast $(30-40 \mathrm{~Hz})$ spontaneous cortical rhythms during brain activation," Journal of Neuroscience, vol. 16, no. 1, pp. 392-417, 1996.

[54] M. Steriade, D. Contreras, F. Amzica, and I. Timofeev, "Synchronization of fast $(30-40 \mathrm{~Hz})$ spontaneous oscillations in intrathalamic and thalamocortical networks," Journal of Neuroscience, vol. 16, no. 8, pp. 2788-2808, 1996.

[55] J. J. Chrobak and G. Buzsáki, "Gamma oscillations in the entorhinal cortex of the freely behaving rat," Journal of Neuroscience, vol. 18, no. 1, pp. 388-398, 1998.

[56] W. H. R. Miltner, C. Braun, M. Arnold, H. Witte, and E. Taub, "Coherence of gamma-band EEG activity as a basis for associative learning," Nature, vol. 397, no. 6718, pp. 434-436, 1999. 
[57] E. Rodriguez, N. George, J. P. Lachaux, J. Martinerie, B. Renault, and F. J. Varela, "Perception's shadow: long-distance synchronization of human brain activity," Nature, vol. 397, no. 6718, pp. 430-433, 1999.

[58] G. Buzsáki, Rhythms of the Brain, Oxford University Press, New York, NY, USA, 2006.

[59] M. Steriade, "Brain electrical activity and sensory processing during waking and sleep states," in Principles and Practice of Sleep Medicine, M. H. Kryger, T. Roth, and W. C. Dement, Eds., pp. 101-119, Elsevier Saunders, Philadelphia, Pa, USA, 4th edition, 2005.

[60] G. Moruzzi and H. W. Magoun, "Brain stem reticular formation and activation of the EEG," Electroencephalography and Clinical Neurophysiology, vol. 1, no. 1-4, pp. 455-473, 1949.

[61] B. E. Jones, "Basic mechanisms of sleep-wake states," in Principles and Practice of Sleep Medicine, M. H. Kryger, T. Roth, and W. C. Dement, Eds., pp. 136-153, Elsevier Saunders, Philadelphia, Pa, USA, 4th edition, 2005.

[62] B. E. Jones, "From waking to sleeping: neuronal and chemical substrates," Trends in Pharmacological Sciences, vol. 26, no. 11, pp. 578-586, 2005.

[63] B. E. Jones, "Modulation of cortical activation and behavioral arousal by cholinergic and orexinergic systems," Annals of the New York Academy of Sciences, vol. 1129, pp. 26-34, 2008.

[64] T. E. Starzl, C. W. Taylor, and H. W. Magoun, "Ascending conduction in reticular activating system, with special reference to the diencephalon," Journal of Neurophysiology, vol. 14, no. 6, pp. 461-477, 1951.

[65] R. E. Brown, D. R. Stevens, and H. L. Haas, "The physiology of brain histamine," Progress in Neurobiology, vol. 63, no. 6, pp. 637-672, 2001.

[66] G. Aston-Jones and F. E. Bloom, "Activity of norepinephrinecontaining locus coeruleus neurons in behaving rats anticipates fluctuations in the sleep-waking cycle," Journal of Neuroscience, vol. 1, no. 8, pp. 876-886, 1981.

[67] M. El Mansari, K. Sakai, and M. Jouvet, "Unitary characteristics of presumptive cholinergic tegmental neurons during the sleep-waking cycle in freely moving cats," Experimental Brain Research, vol. 76, no. 3, pp. 519-529, 1989.

[68] M. Steriade, S. Datta, D. Paré, G. Oakson, and R. Curró Dossi, "Neuronal activities in brain-stem cholinergic nuclei related to tonic activation processes in thalamocortical systems," Journal of Neuroscience, vol. 10, no. 8, pp. 2541-2559, 1990.

[69] M. G. Lee, O. K. Hassani, A. Alonso, and B. E. Jones, "Cholinergic basal forebrain neurons burst with theta during waking and paradoxical sleep," Journal of Neuroscience, vol. 25, no. 17 , pp. 4365-4369, 2005.

[70] J. C. Gillin and N. Sitaram, "Rapid eye movement (REM) sleep: cholinergic mechanisms," Psychological Medicine, vol. 14, no. 3, pp. 501-506, 1984.

[71] B. L. Jacobs and C. A. Fornal, "Activity of brain serotonergic neurons in the behaving animal," Pharmacological Reviews, vol. 43, no. 4, pp. 563-578, 1991.

[72] J. Mirenowicz and W. Schultz, "Preferential activation of midbrain dopamine neurons by appetitive rather than aversive stimuli," Nature, vol. 379, no. 6564, pp. 449-451, 1996.

[73] K. J. Maloney, L. Mainville, and B. E. Jones, "c-Fos expression in dopaminergic and GABAergic neurons of the ventral mesencephalic tegmentum after paradoxical sleep deprivation and recovery," European Journal of Neuroscience, vol. 15, no. 4, pp. 774-778, 2002.

[74] J. J. Hagan, R. A. Leslie, S. Patel et al., "Orexin A activates locus coeruleus cell firing and increases arousal in the rat," Proceedings of the National Academy of Sciences of the United States of America, vol. 96, no. 19, pp. 10911-10916, 1999.
[75] T. L. Horvath, C. Peyron, S. Diano et al., "Hypocretin (orexin) activation and synaptic innervation of the locus coeruleus noradrenergic system," Journal of Comparative Neurology, vol. 415, no. 2, pp. 145-159, 1999.

[76] L. Bayer, M. Serafin, E. Eggermann et al., "Exclusive postsynaptic action of hypocretin-orexin on sublayer $6 \mathrm{~b}$ cortical neurons," Journal of Neuroscience, vol. 24, no. 30, pp. 6760 6764, 2004.

[77] E. Eggermann, M. Serafin, L. Bayer et al., "Orexins/hypocretins excite basal forebrain cholinergic neurones," Neuroscience, vol. 108, no. 2, pp. 177-181, 2001.

[78] K. S. Eriksson, O. Sergeeva, R. E. Brown, and H. L. Haas, "Orexin/hypocretin excites the histaminergic neurons of the tuberomammillary nucleus," Journal of Neuroscience, vol. 21, no. 23, pp. 9273-9279, 2001.

[79] R. J. Liu, A. N. van den Pol, and G. K. Aghajanian, "Hypocretins (orexins) regulate serotonin neurons in the dorsal raphe nucleus by excitatory direct and inhibitory indirect actions," Journal of Neuroscience, vol. 22, no. 21, pp. 94539464, 2002.

[80] M. G. Lee, O. K. Hassani, and B. E. Jones, "Discharge of identified orexin/hypocretin neurons across the sleep-waking cycle," Journal of Neuroscience, vol. 25, no. 28, pp. 6716-6720, 2005.

[81] B. Y. Mileykovskiy, L. I. Kiyashchenko, and J. M. Siegel, "Behavioral correlates of activity in identified hypocretin/orexin neurons," Neuron, vol. 46, no. 5, pp. 787-798, 2005.

[82] R. M. Chemelli, J. T. Willie, C. M. Sinton et al., "Narcolepsy in orexin knockout mice: molecular genetics of sleep regulation," Cell, vol. 98, no. 4, pp. 437-451, 1999.

[83] L. Lin, J. Faraco, R. Li et al., "The sleep disorder canine narcolepsy is caused by a mutation in the hypocretin (orexin) receptor 2 gene," Cell, vol. 98, no. 3, pp. 365-376, 1999.

[84] C. Peyron, J. Faraco, W. Rogers et al., "A mutation in a case of early onset narcolepsy and a generalized absence of hypocretin peptides in human narcoleptic brains," Nature Medicine, vol. 6, no. 9, pp. 991-997, 2000.

[85] R. Szymusiak and D. McGinty, "Sleep-waking discharge of basal forebrain projection neurons in cats," Brain Research Bulletin, vol. 22, no. 2, pp. 423-430, 1989.

[86] Y. Koyama and O. Hayaishi, "Firing of neurons in the preoptic/anterior hypothalamic areas in rat: its possible involvement in slow wave sleep and paradoxical sleep," Neuroscience Research, vol. 19, no. 1, pp. 31-38, 1994.

[87] R. Szymusiak, N. Alam, T. L. Steininger, and D. McGinty, "Sleep-waking discharge patterns of ventrolateral preoptic/anterior hypothalamic neurons in rats," Brain Research, vol. 803, no. 1-2, pp. 178-188, 1998.

[88] M. Modirrousta, L. Mainville, and B. E. Jones, "Gabaergic neurons with $\alpha 2$-adrenergic receptors in basal forebrain and preoptic area express c-Fos during sleep," Neuroscience, vol. 129, no. 3, pp. 803-810, 2004.

[89] J. E. Sherin, P. J. Shiromani, R. W. McCarley, and C. B. Saper, "Activation of ventrolateral preoptic neurons during sleep," Science, vol. 271, no. 5246, pp. 216-219, 1996.

[90] H. Gong, D. McGinty, R. Guzman-Marin, K. T. Chew, D. Stewart, and R. Szymusiak, "Activation of c-fos in GABAergic neurones in the preoptic area during sleep and in response to sleep deprivation," Journal of Physiology, vol. 556, no. 3, pp. 935-946, 2004.

[91] C. B. Saper, T. C. Chou, and T. E. Scammell, "The sleep switch: hypothalamic control of sleep and wakefulness," Trends in Neurosciences, vol. 24, no. 12, pp. 726-731, 2001. 
[92] D. McGinty and R. Szymusiak, "Sleep promoting mechanisms in mammals," in Principles and Practice of Sleep Medicine, M. H. Kryger, T. Roth, and W. C. Dement, Eds., pp. 169-184, Elsevier Saunders, Philadelphia, Pa, USA, 4th edition, 2005.

[93] I. Gritti, L. Mainville, M. Mancia, and B. E. Jones, "GABAergic and other noncholinergic basal forebrain neurons, together with cholinergic neurons, project to the mesocortex and isocortex in the rat," Journal of Comparative Neurology, vol. 383, no. 2, pp. 163-177, 1997.

[94] P. Henny and B. E. Jones, "Projections from basal forebrain to prefrontal cortex comprise cholinergic, GABAergic and glutamatergic inputs to pyramidal cells or interneurons," European Journal of Neuroscience, vol. 27, no. 3, pp. 654-670, 2008.

[95] I. D. Manns, A. Alonso, and B. E. Jones, "Discharge profiles of juxtacellularly labeled and immunohistochemically identified GABAergic basal forebrain neurons recorded in association with the electroencephalogram in anesthetized rats," Journal of Neuroscience, vol. 20, no. 24, pp. 9252-9263, 2000.

[96] O. K. Hassani, M. G. Lee, P. Henny, and B. E. Jones, "Discharge profiles of identified GABAergic in comparison to cholinergic and putative glutamatergic basal forebrain neurons across the sleep-wake cycle," Journal of Neuroscience, vol. 29, no. 38, pp. 11828-11840, 2009.

[97] T. Sakurai, R. Nagata, A. Yamanaka et al., "Input of orexin/hypocretin neurons revealed by a genetically encoded tracer in mice," Neuron, vol. 46, no. 2, pp. 297-308, 2005.

[98] P. Henny and B. E. Jones, "Innervation of orexin/hypocretin neurons by GABAergic, glutamatergic or cholinergic basal forebrain terminals evidenced by immunostaining for presynaptic vesicular transporter and postsynaptic scaffolding proteins," Journal of Comparative Neurology, vol. 499, no. 4, pp. 645-661, 2006.

[99] D. A. McCormick and T. Bal, "Sleep and arousal: thalamocortical mechanisms," Annual Review of Neuroscience, vol. 20, pp. 185-215, 1997.

[100] A. Destexhe and T. J. Sejnowski, "Interactions between membrane conductances underlying thalamocortical slowwave oscillations," Physiological Reviews, vol. 83, no. 4, pp. 1401-1453, 2003.

[101] M. Steriade and R. McCarley, Brain Control of Wakefulness and Sleep, Kluwer Academic, Plenum Publishers, New York, NY, USA, 2005.

[102] H. Jahnsen and R. Llinás, "Voltage-dependent burst-to-tonic switching of thalamic cell activity: an in vitro study," Archives Italiennes de Biologie, vol. 122, no. 1, pp. 73-82, 1984.

[103] E. Carbone and H. D. Lux, "A low voltage-activated, fully inactivating Ca channel in vertebrate sensory neurons," Nature, vol. 310, no. 5977, pp. 501-502, 1984.

[104] E. Carbone and H. D. Lux, "Kinetics and selectivity of a lowvoltage-activated calcium current in chick and rat sensory neurones," Journal of Physiology, vol. 386, pp. 547-570, 1987.

[105] A. P. Fox, M. C. Nowycky, and R. W. Tsien, "Kinetic and pharmacological properties distinguishing three types of calcium currents in chick sensory neurones," Journal of Physiology, vol. 394, pp. 149-172, 1987.

[106] A. Hernandez-Cruz and H. C. Pape, "Identification of two calcium currents in acutely dissociated neurons from the rat lateral geniculate nucleus," Journal of Neurophysiology, vol. 61, no. 6, pp. 1270-1283, 1989.

[107] A. Becchetti, A. Arcangeli, M. R. Del Bene, M. Olivotto, and E. Wanke, "Intra and extracellular surface charges near $\mathrm{Ca}^{2+}$ channels in neurons and neuroblastoma cells," Biophysical Journal, vol. 63, no. 4, pp. 954-965, 1992.

[108] H. Jahnsen and R. Llinás, "Electrophysiological properties of guinea-pig thalamic neurones: an in vitro study," Journal of Physiology, vol. 349, pp. 205-226, 1984.

[109] M. Deschênes, M. Paradis, J. P. Roy, and M. Steriade, "Electrophysiology of neurons of lateral thalamic nuclei in cat: resting properties and burst discharges," Journal of Neurophysiology, vol. 51, no. 6, pp. 1196-1219, 1984.

[110] D. A. McCormick and H. C. Pape, "Properties of a hyperpolarization-activated cation current and its role in rhythmic oscillation in thalamic relay neurones," Journal of Physiology, vol. 431, pp. 291-318, 1990.

[111] D. A. McCormick and H. C. Pape, "Noradrenergic and serotonergic modulation of a hyperpolarization-activated cation current in thalamic relay neurones," Journal of Physiology, vol. 431, pp. 319-342, 1990.

[112] D. A. McCormick and J. R. Huguenard, "A model of the electrophysiological properties of thalamocortical relay neurons," Journal of Neurophysiology, vol. 68, no. 4, pp. 13841400, 1992.

[113] S. Murray Sherman and R. W. Guillery, Exploring the Thalamus and Its Role in Cortical Function, The MIT Press, Cambridge, Mass, USA, 2nd edition, 2006.

[114] M. Steriade, M. Deschênes, L. Domich, and C. Mulle, "Abolition of spindle oscillations in thalamic neurons disconnected from nucleus reticularis thalami," Journal of Neurophysiology, vol. 54, no. 6, pp. 1473-1497, 1985.

[115] M. Steriade, L. Domich, G. Oakson, and M. Deschênes, “The deafferented reticular thalamic nucleas generates spindle rhythmicity," Journal of Neurophysiology, vol. 57, no. 1, pp. 260-273, 1987.

[116] D. Contreras, A. Destexhe, T. J. Sejnowski, and M. Steriade, "Control of spatiotemporal coherence of a thalamic oscillation by corticothalamic feedback," Science, vol. 274, no. 5288, pp. 771-774, 1996.

[117] I. Timofeev, D. Contreras, and M. Steriade, "Synaptic responsiveness of cortical and thalamic neurones during various phases of slow sleep oscillation in cat," Journal of Physiology, vol. 494, no. 1, pp. 265-278, 1996.

[118] M. Steriade, I. Timofeev, F. Grenier, and N. Dürmüller, "Role of thalamic and cortical neurons in augmenting responses and self- sustained activity: dual intracellular recordings in vivo," Journal of Neuroscience, vol. 18, no. 16, pp. 6425-6443, 1998.

[119] I. Timofeev, F. Grenier, M. Bazhenov, A. R. Houweling, T. J. Sejnowski, and M. Steriade, "Short-and medium-term plasticity associated with augmenting responses in cortical slabs and spindles in intact cortex of cats in vivo," Journal of Physiology, vol. 542, no. 2, pp. 583-598, 2002.

[120] M. Steriade, A. Nunez, and F. Amzica, "Intracellular analysis of relations between the slow $(<1 \mathrm{~Hz})$ neocortical oscillation and other sleep rhythms of the electroencephalogram," Journal of Neuroscience, vol. 13, no. 8, pp. 3266-3283, 1993.

[121] M. Steriade, R. C. Dossi, and A. Nunez, "Network modulation of a slow intrinsic oscillation of cat thalamocortical neurons implicated in sleep delta waves: cortically induced synchronization and brainstem cholinergic suppression," Journal of Neuroscience, vol. 11, no. 10, pp. 3200-3217, 1991.

[122] F. Amzica and M. Steriade, "Disconnection of intracortical synaptic linkages disrupts synchronization of a slow oscillation," Journal of Neuroscience, vol. 15, no. 6, pp. 4658-4677, 1995. 
[123] I. Timofeev and M. Steriade, "Low-frequency rhythms in the thalamus of intact-cortex and decorticated cats," Journal of Neurophysiology, vol. 76, no. 6, pp. 4152-4168, 1996.

[124] D. Contreras and M. Steriade, "Cellular basis of EEG slow rhythms: a study of dynamic corticothalamic relationships," Journal of Neuroscience, vol. 15, no. 1, pp. 604-622, 1995.

[125] P. Achermann and A. A. Borbély, "Low-frequency $(<1 \mathrm{~Hz})$ oscillations in the human sleep electroencephalogram," Neuroscience, vol. 81, no. 1, pp. 213-222, 1997.

[126] D. Pare, Y. Smith, A. Parent, and M. Steriade, "Projections of brainstem core cholinergic and non-cholinergic neurons of cat to intralaminar and reticular thalamic nuclei," Neuroscience, vol. 25, no. 1, pp. 69-86, 1988.

[127] Y. Smith, D. Pare, M. Deschênes, A. Parent, and M. Steriade, "Cholinergic and non-cholinergic projections from the upper brainstem core to the visual thalamus in the cat," Experimental Brain Research, vol. 70, no. 1, pp. 166-180, 1988.

[128] M. Steriade, D. Pare, A. Parent, and Y. Smith, "Projections of cholinergic and non-cholinergic neurons of the brainstem core to relay and associational thalamic nuclei in the cat and macaque monkey," Neuroscience, vol. 25, no. 1, pp. 47-67, 1988.

[129] R. C. Dossi, D. Pare, and M. Steriade, "Short-lasting nicotinic and long-lasting muscarinic depolarizing responses of thalamocortical neurons to stimulation of mesopontine cholinergic nuclei," Journal of Neurophysiology, vol. 65, no. 3, pp. 393-406, 1991.

[130] B. Hu, M. Steriade, and M. Deschênes, "The effects of brainstem peribrachial stimulation on perigeniculate neurons: the blockage of spindle waves," Neuroscience, vol. 31, no. 1, pp. 1-12, 1989.

[131] M. Steriade, K. Sakai, and M. Jouvet, "Bulbo-thalamic neurons related to thalamocortical activation processes during paradoxical sleep," Experimental Brain Research, vol. 54, no. 3, pp. 463-475, 1984.

[132] M. Steriade, A. Parent, D. Pare, and Y. Smith, "Cholinergic and non-cholinergic neurons of cat basal forebrain project to reticular and mediodorsal thalamic nuclei," Brain Research, vol. 408, no. 1-2, pp. 372-376, 1987.

[133] M. Steriade, "Synchronized activities of coupled oscillators in the cerebral cortex and thalamus at different levels of vigilance," Cerebral Cortex, vol. 7, no. 6, pp. 583-588, 1997.

[134] R. Llinás and U. Ribary, "Coherent 40-Hz oscillation characterizes dream state in humans," Proceedings of the National Academy of Sciences of the United States of America, vol. 90, no. 5, pp. 2078-2081, 1993.

[135] L. L. Iversen, S. D. Iversen, F. E. Bloom, and R. H. Roth, Introduction To Neuropsychopharmacology, Oxford University Press, New York, NY, USA, 2009.

[136] C. R. Houser, G. D. Crawford, and R. P. Barber, "Organization and morphological characteristics of cholinergic neurons: an immunocytochemical study with a monoclonal antibody to choline acetyltransferase," Brain Research, vol. 266, no. 1, pp. 97-119, 1983.

[137] D. M. Armstrong, C. B. Saper, and A. I. Levey, "Distribution of cholinergic neurons in rat brain: deomonstrated by the immunocytochemical localization of choline acetyltransferase," Journal of Comparative Neurology, vol. 216, no. 1, pp. 53-68, 1983.

[138] U. Arvidsson, M. Riedl, R. Elde, and B. Meister, "Vesicular acetylcholine transporter (VAChT) protein: a novel and unique marker for cholinergic neurons in the central and peripheral nervous system," Journal of Comparative Neurology, vol. 378, no. 4, pp. 454-467, 1997.

[139] J. D. Erickson, H. Varoqui, M. K. H. Schafer et al., "Functional identification of a vesicular acetylcholine transporter and its expression from a "cholinergic" gene locus," Journal of Biological Chemistry, vol. 269, no. 35, pp. 21929-21932, 1994.

[140] J. D. Erickson, E. Weihe, M. K. M. Schafer et al., "The VAChT/ChAT "cholinergic gene locus": new aspects of genetic and vesicular regulation of cholinergic function," Progress in Brain Research, vol. 109, pp. 69-82, 1996.

[141] T. Okuda, T. Haga, Y. Kanai, H. Endou, T. Ishihara, and I. Katsura, "Identification and characterization of the highaffinity choline transporter," Nature Neuroscience, vol. 3, no. 2, pp. 120-125, 2000.

[142] S. Apparsundaram, S. M. Ferguson, A. L. George, and R. D. Blakely, "Molecular cloning of a human, hemicholinium3-sensitive choline transporter," Biochemical and Biophysical Research Communications, vol. 276, no. 3, pp. 862-867, 2000.

[143] D. A. McCormick, H. C. Pape, and A. Williamson, "Actions of norepinephrine in the cerebral cortex and thalamus: implications for function of the central noradrenergic system," Progress in Brain Research, vol. 88, pp. 293-305, 1991.

[144] D. A. McCormick, "Neurotransmitter actions in the thalamus and cerebral cortex and their role in neuromodulation of thalamocortical activity," Progress in Neurobiology, vol. 39, no. 4, pp. 337-388, 1992.

[145] M. Sarter, W. J. Gehring, and R. Kozak, "More attention must be paid: the neurobiology of attentional effort," Brain Research Reviews, vol. 51, no. 2, pp. 145-160, 2006.

[146] K. Guillem, B. Bloem, R. B. Poorthuis et al., "Nicotinic acetylcholine receptor $\beta 2$ subunits in the medial prefrontal cortex control attention," Science, vol. 333, no. 6044, pp. 888-891, 2011.

[147] H. H. Jasper and J. Tessier, "Acetylcholine liberation from cerebral cortex during paradoxical (REM) sleep," Science, vol. 172, no. 3983, pp. 601-602, 1971.

[148] K. Krnjević, R. Pumain, and L. Renaud, "The mechanism of excitation by acetylcholine in the cerebral cortex," Journal of Physiology, vol. 215, no. 1, pp. 247-268, 1971.

[149] M. R. Picciotto, M. Zoli, C. Lena et al., "Abnormal avoidance learning in mice lacking functional high-affinity nicotine receptor in the brain," Nature, vol. 374, no. 6517, pp. 65-67, 1995.

[150] M. R. Picciotto, M. Zoli, R. Rimondini et al., "Acetylcholine receptors containing the $\beta 2$ subunit are involved in the reinforcing properties of nicotine," Nature, vol. 391, no. 6663, pp. 173-177, 1998.

[151] B. Hahn, C. G. V. Sharples, S. Wonnacott, M. Shoaib, and I. P. Stolerman, "Attentional effects of nicotinic agonists in rats," Neuropharmacology, vol. 44, no. 8, pp. 1054-1067, 2003.

[152] C. D. C. Bailey, M. De Biasi, P. J. Fletcher, and E. K. Lambe, "The nicotinic acetylcholine receptor $\alpha 5$ subunit plays a key role in attention circuitry and accuracy," Journal of Neuroscience, vol. 30, no. 27, pp. 9241-9252, 2010.

[153] W. M. Howe, J. Ji, V. Parikh et al., "Enhancement of attentional performance by selective stimulation of $\alpha 4 \beta 2 *$ nAChRs: underlying cholinergic mechanisms," Neuropsychopharmacology, vol. 35, no. 6, pp. 1391-1401, 2010.

[154] B. Lendvai and E. S. Vizi, "Nonsynaptic chemical transmission through nicotinic acetylcholine receptors," Physiological Reviews, vol. 88, no. 2, pp. 333-349, 2008.

[155] G. Pepeu and M. G. Giovannini, "Changes in acetylcholine extracellular levels during cognitive processes," Learning and Memory, vol. 11, no. 1, pp. 21-27, 2004. 
[156] P. Turrini, M. A. Casu, T. P. Wong, Y. De Koninck, A. Ribeiroda-Silva, and A. C. Cuello, "Cholinergic nerve terminals establish classical synapses in the rat cerebral cortex: synaptic pattern and age-related atrophy," Neuroscience, vol. 105, no. 2, pp. 277-285, 2001.

[157] D. Umbriaco, K. C. Watkins, L. Descarries, C. Cozzari, and B. K. Hartman, "Ultrastructural and morphometric features of the acetylcholine innervation in adult rat parietal cortex: an electron microscopic study in serial sections," Journal of Comparative Neurology, vol. 348, no. 3, pp. 351-373, 1994.

[158] L. Mrzljak, M. Pappy, C. Leranth, and P. S. Goldman-Rakic, "Cholinergic synaptic circuitry in the macaque prefrontal cortex," Journal of Comparative Neurology, vol. 357, no. 4, pp. 603-617, 1995.

[159] P. Aracri, S. Consonni, R. Morini et al., "Tonic modulation of GABA release by nicotinic acetylcholine receptors in layer v of the murine prefrontal cortex," Cerebral Cortex, vol. 20, no. 7, pp. 1539-1555, 2010.

[160] A. J. Graham, C. M. Martin-Ruiz, T. Teaktong, M. A. Ray, and J. A. Court, "Human brain nicotinic receptors, their distribution and participation in neuropsychiatric disorders," Current Drug Targets, vol. 1, no. 4, pp. 387-397, 2002.

[161] J. von Engelhardt, M. Eliava, A. H. Meyer, A. Rozov, and H. Monyer, "Functional characterization of intrinsic cholinergic interneurons in the cortex," Journal of Neuroscience, vol. 27, no. 21, pp. 5633-5642, 2007.

[162] N. Mechawar and L. Descarries, "The cholinergic innervation develops early and rapidly in the rat cerebral cortex: a quantitative immunocytochemical study," Neuroscience, vol. 108, no. 4, pp. 555-567, 2001.

[163] S. Consonni, S. Leone, A. Becchetti, and A. Amadeo, "Developmental and neurochemical features of cholinergic neurons in the murine cerebral cortex," BMC Neuroscience, vol. 10, article 18, 2009.

[164] M. De Fusco, A. Becchetti, A. Patrignani et al., "The nicotinic receptor $\beta 2$ subunit is mutant in nocturnal frontal lobe epilepsy," Nature Genetics, vol. 26, no. 3, pp. 275-276, 2000.

[165] H. A. Phillips, I. Favre, M. Kirkpatrick et al., "CHRNB2 is the second acetylcholine receptor subunit associated with autosomal dominant nocturnal frontal lobe epilepsy," American Journal of Human Genetics, vol. 68, no. 1, pp. 225-231, 2001.

[166] C. Vidal and J. P. Changeux, "Nicotinic acid and muscarinic modulations of excitatory synaptic transmission in the rat prefrontal cortex in vitro," Neuroscience, vol. 56, no. 1, pp. 23-32, 1993.

[167] Z. Gil, B. W. Connors, and Y. Amitai, "Differential regulation of neocortical synapses by neuromodulators and activity," Neuron, vol. 19, no. 3, pp. 679-686, 1997.

[168] Y. Gioanni, "Nicotinic receptors in the rat prefrontal cortex: increase in glutamate release and facilitation of mediodorsal thalamo-cortical transmission," European Journal of Neuroscience, vol. 11, no. 1, pp. 18-30, 1999.

[169] E. K. Lambe, M. R. Picciotto, and G. K. Aghajanian, "Nicotine induces glutamate release from thalamocortical terminals in prefrontal cortex," Neuropsychopharmacology, vol. 28, no. 2, pp. 216-225, 2003.

[170] Z. G. Chu, F. M. Zhou, and J. J. Hablitz, "Nicotinic acetylcholine receptor-mediated synaptic potentials in rat neocortex," Brain Research, vol. 887, no. 2, pp. 399-405, 2000.

[171] G. Zolles, E. Wagner, A. Lampert, and B. Sutor, "Functional expression of nicotinic acetylcholine receptors in rat neocortical layer 5 pyramidal cells," Cerebral Cortex, vol. 19, no. 5, pp. 1079-1091, 2009.
[172] S. M. Kassam, P. M. Herman, N. M. Goodfellow, N. C. Alves, and E. K. Lambe, "Developmental excitation of corticothalamic neurons by nicotinic acetylcholine receptors," Journal of Neuroscience, vol. 28, no. 35, pp. 8756-8764, 2008.

[173] E. K. Lambe, P. Olausson, N. K. Horst, J. R. Taylor, and G. K. Aghajanian, "Hypocretin and nicotine excite the same thalamocortical synapses in prefrontal cortex: correlation with improved attention in rat," Journal of Neuroscience, vol. 25, no. 21, pp. 5225-5229, 2005.

[174] J. J. Couey, R. M. Meredith, S. Spijker et al., "Distributed network actions by nicotine increase the threshold for spiketiming-dependent plasticity in prefrontal cortex," Neuron, vol. 54, no. 1, pp. 73-87, 2007.

[175] R. B. Poorthuis, B. Bloem, B. Schak, J. Wester, C. P. de Kock, and H. D. Mansvelder, "Layer-specific modulation of the prefrontal cortex by nicotinic acetylcholine receptors," Cerebral Cortex. In press.

[176] H. B. M. Uylings, H. J. Groenewegen, and B. Kolb, "Do rats have a prefrontal cortex?" Behavioural Brain Research, vol. 146, no. 1-2, pp. 3-17, 2003.

[177] P. L. A. Gabbott, T. A. Warner, P. R. L. Jays, P. Salway, and S. J. Busby, "Prefrontal cortex in the rat: projections to subcortical autonomic, motor, and limbic centers," Journal of Comparative Neurology, vol. 492, no. 2, pp. 145-177, 2005.

[178] K. A. Richardson, E. E. Fanselow, and B. W. Connors, "Neocortical anatomy and physiology," in Epilepsy. A Comprehensive Textbook, J. Engel Jr. and T. A. Pedley, Eds., pp. 323335, Lippincott Williams and Wilkins, Philadelphia, Pa, USA, 2008.

[179] Z. Xiang, J. R. Huguenard, and D. A. Prince, "Cholinergic switching within neocortical inhibitory networks," Science, vol. 281, no. 5379, pp. 985-988, 1998.

[180] J. T. Porter, B. Cauli, K. Tsuzuki, B. Lambolez, J. Rossier, and E. Audinat, "Selective excitation of subtypes of neocortical interneurons by nicotinic receptors," Journal of Neuroscience, vol. 19, no. 13, pp. 5228-5235, 1999.

[181] E. Christophe, A. Roebuck, J. F. Staiger, D. J. Lavery, S. Charpak, and E. Audinat, "Two types of nicotinic receptors mediate an excitation of neocortical layer I interneurons," Journal of Neurophysiology, vol. 88, no. 3, pp. 1318-1327, 2002.

[182] M. Alkondon, E. F. R. Pereira, H. M. Eisenberg, and E. X. Albuquerque, "Nicotinic receptor activation in human cerebral cortical interneurons: a mechanism for inhibition and disinhibition of neuronal networks," Journal of Neuroscience, vol. 20, no. 1, pp. 66-75, 2000.

[183] A. Klaassen, J. Glykys, J. Maguire, C. Labarca, I. Mody, and J. Boulter, "Seizures and enhanced cortical GABAergic inhibition in two mouse models of human autosomal dominant nocturnal frontal lobe epilepsy," Proceedings of the National Academy of Sciences of the United States of America, vol. 103, no. 50, pp. 19152-19157, 2006.

[184] L. L. McMahon, K. W. Yoon, and V. A. Chiappinelli, "Electrophysiological evidence for presynaptic nicotinic receptors in the avian ventral lateral geniculate nucleus," Journal of Neurophysiology, vol. 71, no. 2, pp. 826-829, 1994.

[185] J. Z. Guo, T. L. Tredway, and V. A. Chiappinelli, "Glutamate and GABA release are enhanced by different subtypes of presynaptic nicotinic receptors in the lateral geniculate nucleus," Journal of Neuroscience, vol. 18, no. 6, pp. 1963-1969, 1998.

[186] C. Lena and J. P. Changeux, "Role of $\mathrm{Ca}^{2+}$ ions in nicotinic facilitation of GABA release in mouse thalamus," Journal of Neuroscience, vol. 17, no. 2, pp. 576-585, 1997. 
[187] J. Z. Guo, Y. Liu, E. M. Sorenson, and V. A. Chiappinelli, "Synaptically released and exogenous ACh activates different nicotinic receptors to enhance evoked glutamatergic transmission in the lateral geniculate nucleus," Journal of Neurophysiology, vol. 94, no. 4, pp. 2549-2560, 2005.

[188] J. Z. Guo, E. M. Sorenson, and V. A. Chiappinelli, "Cholinergic modulation of non-N-methyl-D-aspartic acid glutamatergic transmission in the chick ventral lateral geniculate nucleus," Neuroscience, vol. 166, no. 2, pp. 604-614, 2010.

[189] E. G. Jones, "GABAergic neurons and their role in cortical plasticity in primates," Cerebral Cortex, vol. 3, no. 5, pp. 361372, 1993.

[190] H. Markram, M. Toledo-Rodriguez, Y. Wang, A. Gupta, G. Silberberg, and $\mathrm{C}$. Wu, "Interneurons of the neocortical inhibitory system," Nature Reviews Neuroscience, vol. 5, no. 10, pp. 793-807, 2004.

[191] H. S. Meyer, D. Schwarz, V. C. Wimmer et al., "Inhibitory interneurons in a cortical column form hot zones of inhibition in layers 2 and 5A," Proceedings of the National Academy of Sciences of the United States of America, vol. 108, no. 40, pp. 16807-16812, 2011.

[192] A. Peters, B. R. Payne, and K. Josephson, "Transcallosal nonpyramidal cell projections from visual cortex in the cat," Journal of Comparative Neurology, vol. 302, no. 1, pp. 124$142,1990$.

[193] M. Fabri and T. Manzoni, "Glutamic acid decarboxylase immunoreactivity in callosal projecting neurons of cat and rat somatic sensory areas," Neuroscience, vol. 123, no. 2, pp. 557-566, 2004.

[194] S. Higo, N. Udaka, and N. Tamamaki, "Long-range GABAergic projection neurons in the cat neocortex," Journal of Comparative Neurology, vol. 503, no. 3, pp. 421-431, 2007.

[195] S. Higo, K. Akashi, K. Sakimura, and N. Tamamaki, "Subtypes of GABAergic neurons project axons in the neocortex," Frontiers in Neuroanatomy, vol. 3, article 25, 2009.

[196] C. T. McDonald and A. Burkhalter, "Organization of longrange inhibitory connections within rat visual cortex," Journal of Neuroscience, vol. 13, no. 2, pp. 768-781, 1993.

[197] Y. A. Gonchar, P. B. Johnson, and R. J. Weinberg, "GABAimmunopositive neurons in rat neocortex with contralateral projections to S-I," Brain Research, vol. 697, no. 1-2, pp. 2734, 1995.

[198] V. Aroniadou-Anderjaska and A. Keller, "Intrinsic inhibitory pathways in mouse barrel cortex," NeuroReport, vol. 7, no. 14, pp. 2363-2368, 1996.

[199] M. Fabri and T. Manzoni, "Glutamate decarboxylase immunoreactivity in corticocortical projecting neurons of rat somatic sensory cortex," Neuroscience, vol. 72, no. 2, pp. 435-448, 1996.

[200] R. Tomioka, K. Okamoto, T. Furuta et al., "Demonstration of long-range GABAergic connections distributed throughout the mouse neocortex," European Journal of Neuroscience, vol. 21, no. 6, pp. 1587-1600, 2005.

[201] R. Tomioka and K. S. Rockland, "Long-distance corticocortical GABAergic neurons in the adult monkey white and gray matter," Journal of Comparative Neurology, vol. 505, no. 5, pp. 526-538, 2007.

[202] N. Tamamaki and R. Tomioka, "Long-range GABAergic connections distributed throughout the neocortex and their possible function," Frontiers in Neuroscience, vol. 4, article 202, 2010.

[203] J. J. Soghomonian and D. L. Martin, "Two isoforms of glutamate decarboxylase: why?" Trends in Pharmacological Sciences, vol. 19, no. 12, pp. 500-505, 1998.
[204] L. Li, J. Jiang, W. A. Hagopian et al., "Differential detection of rat islet and brain glutamic acid decarboxylase (GAD) isoforms with sequence-specific peptide antibodies," Journal of Histochemistry and Cytochemistry, vol. 43, no. 1, pp. 53-59, 1995.

[205] S. L. McIntire, R. J. Reimer, K. Schuske, R. H. Edwards, and E. M. Jorgensen, "Identification and characterization of the vesicular GABA transporter," Nature, vol. 389, no. 6653, pp. 870-876, 1997.

[206] C. Sagné, S. El Mestikawy, M. F. Isambert et al., "Cloning of a functional vesicular GABA and glycine transporter by screening of genome databases," FEBS Letters, vol. 417, no. 2, pp. 177-183, 1997.

[207] F. A. Chaudhry, R. J. Reimer, E. E. Bellocchio et al., "The vesicular GABA transporter, VGAT, localizes to synaptic vesicles in sets of glycinergic as well as GABAergic neurons," Journal of Neuroscience, vol. 18, no. 23, pp. 9733-9750, 1998.

[208] E. A. Schwartz, "Calcium-independent release of GABA from isolated horizontal cells of the toad retina," Journal of Physiology, vol. 323, pp. 211-227, 1982.

[209] S. Yazulla and J. Kleinschmidt, "Carrier-mediated release of GABA from retinal horizontal cells," Brain Research, vol. 263, no. 1, pp. 63-75, 1983.

[210] J. P. Pin and J. Bockaert, "Two distinct mechanisms, differentially affected by excitatory amino acids, trigger GABA release from fetal mouse striatal neurons in primary culture," Journal of Neuroscience, vol. 9, no. 2, pp. 648-656, 1989.

[211] V. Gallo, M. Patrizio, and G. Levi, "GABA release triggered by the activation of neuron-like non-NMDA receptors in cultured type 2 astrocytes is carrier-mediated," Glia, vol. 4, no. 3, pp. 245-255, 1991.

[212] S. Bernath, "Calcium-independent release of amino acid neurotransmitters: fact or artifact?" Progress in Neurobiology, vol. 38, no. 1, pp. 57-91, 1992.

[213] D. Attwell, B. Barbour, and M. Szatkowski, "Nonvesicular release of neurotransmitter," Neuron, vol. 11, no. 3, pp. 401407, 1993.

[214] U. Koch and A. K. Magnusson, "Unconventional GABA release: mechanisms and function," Current Opinion in Neurobiology, vol. 19, no. 3, pp. 305-310, 2009.

[215] N. B. Hamilton and D. Attwell, "Do astrocytes really exocytose neurotransmitters?" Nature Reviews Neuroscience, vol. 11, no. 4, pp. 227-238, 2010.

[216] M. C. Angulo, K. Le Meur, A. S. Kozlov, S. Charpak, and E. Audinat, "GABA, a forgotten gliotransmitter," Progress in Neurobiology, vol. 86, no. 3, pp. 297-303, 2008.

[217] I. E. Scheffer, K. P. Bhatia, I. Lopes-Cendes et al., "Autosomal dominant frontal epilepsy misdiagnosed as sleep disorder," The Lancet, vol. 343, no. 8896, pp. 515-517, 1994.

[218] I. E. Scheffer, K. P. Bhatia, I. Lopes-Cendes et al., "Autosomal dominant nocturnal frontal lobe epilepsy: a distinctive clinical disorder," Brain, vol. 118, no. 1, pp. 61-73, 1995.

[219] W. T. Blume, H. O. Lüders, E. Mizrahi, C. Tassinari, W. Van Emde Boas, and J. Engel, "Glossary of descriptive terminology for ictal semiology: report of the ILAE Task Force on classification and terminology," Epilepsia, vol. 42, no. 9, pp. 1212-1218, 2001.

[220] R. Combi, L. Dalprà, M. L. Tenchini, and L. Ferini-Strambi, "Autosomal dominant nocturnal frontal lobe epilepsy: a critical overview," Journal of Neurology, vol. 251, no. 8, pp. 923-934, 2004.

[221] F. Provini, G. Plazzi, P. Tinuper, S. Vandi, E. Lugaresi, and P. Montagna, "Nocturnal frontal lobe epilepsy: a clinical and polygraphic overview of 100 consecutive cases," Brain, vol. 122, no. 6, pp. 1017-1031, 1999. 
[222] F. Picard and E. Brodtkorb, "Familial frontal lobe epilepsy," in Epilepsy. A Comprehensive Textbook, J. Engel Jr and T. A. Pedley, Eds., pp. 2495-2502, Lippincott Williams and Wilkins, Philadelphia, Pa, USA, 2nd edition, 2008.

[223] F. Picard, A. J. Pegna, V. Arntsberg et al., "Neuropsychological disturbances in frontal lobe epilepsy due to mutated nicotinic receptors," Epilepsy and Behavior, vol. 14, no. 2, pp. 354-359, 2009.

[224] M. L. Tenchini, S. Duga, M. T. Bonati et al., "Ser252Phe and 776ins3 mutations in the CHRNA4 gene are rare in the Italian ADNFLE population," Sleep, vol. 22, no. 5, pp. 637639, 1999.

[225] O. K. Steinlein, A. Magnusson, J. Stoodt et al., "An insertion mutation of the CHRNA4 gene in a family with autosomal dominant nocturnal frontal lobe epilepsy," Human Molecular Genetics, vol. 6, no. 6, pp. 943-947, 1997.

[226] O. K. Steinlein, J. Stoodt, J. Mulley, S. Berkovic, I. E. Scheffer, and E. Brodtkorb, "Independent occurrence of the CHRNA4 Ser248Phe mutation in a Norwegian family with nocturnal frontal lobe epilepsy," Epilepsia, vol. 41, no. 5, pp. 529-535, 2000.

[227] S. Hirose, H. Iwata, H. Akiyoshi et al., "A novel mutation of CHRNA4 responsible for autosomal dominant nocturnal frontal lobe epilepsy," Neurology, vol. 53, no. 8, pp. 1749$1753,1999$.

[228] T. Leniger, C. Kananura, A. Hufnagel, S. Bertrand, D. Bertrand, and O. K. Steinlein, "A new Chrna4 mutation with low penetrance in nocturnal frontal lobe epilepsy," Epilepsia, vol. 44, no. 7, pp. 981-985, 2003.

[229] F. Díaz-Otero, M. Quesada, J. Morales-Corraliza, C. Martínez-Parra, P. Gómez-Garre, and J. M. Serratosa, "Autosomal dominant nocturnal frontal lobe epilepsy with a mutation in the CHRNB2 gene," Epilepsia, vol. 49, no. 3, pp. 516$520,2008$.

[230] D. Bertrand, F. Elmslie, E. Hughes et al., "The CHRNB2 mutation $\mathrm{I} 312 \mathrm{M}$ is associated with epilepsy and distinct memory deficits," Neurobiology of Disease, vol. 20, no. 3, pp. 799-804, 2005.

[231] J. C. Hoda, W. Gu, M. Friedli et al., "Human nocturnal frontal lobe epilepsy: pharmocogenomic profiles of pathogenic nicotinic acetylcholine receptor $\beta$-subunit mutations outside the ion channel pore," Molecular Pharmacology, vol. 74, no. 2, pp. 379-391, 2008.

[232] W. Gu, D. Bertrand, and O. K. Steinlein, "A major role of the nicotinic acetylcholine receptor gene CHRNA2 in autosomal dominant nocturnal frontal lobe epilepsy (ADNFLE) is unlikely," Neuroscience Letters, vol. 422, no. 1, pp. 74-76, 2007.

[233] R. Combi, L. Ferini-Strambi, and M. Luisa Tenchini, "CHRNA2 mutations are rare in the NFLE population: evaluation of a large cohort of Italian patients," Sleep Medicine, vol. 10, no. 1, pp. 139-142, 2009.

[234] S. Hirose and H. Kurahashi H, "Autosomal dominant nocturnal frontal lobe epilepsy," R. A. Pagon, T. C. Bird, C. R. Dolan, and K. Stephens, Eds., University of Washington, Seattle, Wash, USA, 2010.

[235] Y. Chen, L. Wu, Y. Fang et al., "A novel mutation of the nicotinic acetylcholine receptor gene CHRNA4 in sporadic nocturnal frontal lobe epilepsy," Epilepsy Research, vol. 83, no. 23, pp. 152-156, 2009.

[236] H. Liu, C. Lu, Z. Li et al., "The identification of a novel mutation of nicotinic acetylcholine receptor gene CHRNB2 in a Chinese patient: its possible implication in non-familial nocturnal frontal lobe epilepsy," Epilepsy Research, vol. 95, no. 1-2, pp. 94-99, 2011.
[237] H. A. Phillips, I. E. Scheffer, K. M. Crossland et al., "Autosomal dominant nocturnal frontal-lobe epilepsy: genetic heterogeneity and evidence for a second locus at 15q24," American Journal of Human Genetics, vol. 63, no. 4, pp. 11081116,1998

[238] R. Combi, L. Dalprà, L. Ferini-Strambi, and M. L. Tenchini, "Frontal lobe epilepsy and mutations of the corticotropinreleasing hormone gene," Annals of Neurology, vol. 58, no. 6, pp. 899-904, 2005.

[239] S. R. Vincent, K. Satoh, and D. M. Armstrong, "Neuropeptides and NADPH-diaphorase activity in the ascending cholinergic reticular system of the rat," Neuroscience, vol. 17, no. 1, pp. 167-182, 1986.

[240] H. Okuda, S. Shioda, Y. Nakai, H. Nakayama, M. Okamoto, and T. Nakashima, "The presence of corticotropin-releasing factor-like immunoreactive synaptic vesicles in axon terminals with nicotinic acetylcholine receptor-like immunoreactivity in the median eminence of the rat," Neuroscience Letters, vol. 161, no. 2, pp. 183-186, 1993.

[241] H. P. Jedema and A. A. Grace, "Corticotropin-releasing hormone directly activates noradrenergic neurons of the locus ceruleus recorded in vitro," Journal of Neuroscience, vol. 24, no. 43, pp. 9703-9713, 2004.

[242] C. Cirelli and G. Tononi, "Gene expression in the brain across the sleep-waking cycle," Brain Research, vol. 885, no. 2, pp. 303-321, 2000.

[243] C. Léna, D. Popa, R. Grailhe, P. Escourrou, J. P. Changeux, and J. Adrien, " $\beta 2$-Containing nicotinic receptors contribute to the organization of sleep and regulate putative microarousals in mice," Journal of Neuroscience, vol. 24, no. 25, pp. 5711-5718, 2004.

[244] F. Picard, D. Bruel, D. Servent et al., "Alteration of the in vivo nicotinic receptor density in ADNFLE patients: a PET study," Brain, vol. 129, no. 8, pp. 2047-2060, 2006.

[245] C. Di Resta, P. Ambrosi, G. Curia, and A. Becchetti, "Effect of carbamazepine and oxcarbazepine on wild-type and mutant neuronal nicotinic acetylcholine receptors linked to nocturnal frontal lobe epilepsy," European Journal of Pharmacology, vol. 643, no. 1, pp. 13-20, 2010.

[246] J. C. Hoda, M. Wanischeck, D. Bertrand, and O. K. Steinlein, "Pleiotropic functional effects of the first epilepsy-associated mutation in the human CHRNA2 gene," FEBS Letters, vol. 583, no. 10, pp. 1599-1604, 2009.

[247] M. Kishi and J. H. Steinbach, "Role of the agonist binding site in up-regulation of neuronal nicotinic $\alpha 4 \beta 2$ receptors," Molecular Pharmacology, vol. 70, no. 6, pp. 2037-2044, 2006.

[248] S. Weiland, V. Witzemann, A. Villarroel, P. Propping, and O. Steinlein, "An amino acid exchange in the second transmembrane segment of a neuronal nicotinic receptor causes partial epilepsy by altering its desensitization kinetics," FEBS Letters, vol. 398, no. 1, pp. 91-96, 1996.

[249] A. Kuryatov, V. Gerzanich, M. Nelson, F. Olale, and J. Lindstrom, "Mutation causing autosomal dominant nocturnal frontal lobe epilepsy alters $\mathrm{Ca}^{2+}$ permeability, conductance, and gating of human $\alpha 4 \beta 2$ nicotinic acetylcholine receptors," Journal of Neuroscience, vol. 17, no. 23, pp. 9035-9047, 1997.

[250] S. Bertrand, S. Weiland, S. F. Berkovic, O. K. Steinlein, and D. Bertrand, "Properties of neuronal nicotinic acetylcholine receptor mutants from humans suffering from autosomal dominant nocturnal frontal lobe epilepsy," British Journal of Pharmacology, vol. 125, no. 4, pp. 751-760, 1998.

[251] B. Moulard, F. Picard, S. Le Hellard et al., "Ion channel variation causes epilepsies," Brain Research Reviews, vol. 36, no. 2-3, pp. 275-284, 2001. 
[252] D. Bertrand, F. Picard, S. Le Hellard et al., "How mutations in the nAChRs can cause ADNFLE epilepsy," Epilepsia, vol. 43, supplement s5, pp. 112-122, 2002.

[253] V. Itier and D. Bertrand, "Mutations of the neuronal nicotinic acetylcholine receptors and their association with ADNFLE," Neurophysiologie Clinique, vol. 32, no. 2, pp. 99-107, 2002.

[254] A. Figl, N. Viseshakul, N. Shafaee, J. Forsayeth, and B. N. Cohen, "Two mutations linked to nocturnal frontal lobe epilepsy cause use-dependent potentiation of the nicotinic ACh response," Journal of Physiology, vol. 513, no. 3, pp. 655-670, 1998.

[255] N. Matsushima, S. Hirose, H. Iwata et al., "Mutation (Ser284Leu) of neuronal nicotinic acetylcholine receptor $\alpha 4$ subunit associated with frontal lobe epilepsy causes faster desensitization of the rat receptor expressed in oocytes," Epilepsy Research, vol. 48, no. 3, pp. 181-186, 2002.

[256] N. Rodrigues-Pinguet, L. Jia, M. Li et al., "Five ADNFLE mutations reduce the $\mathrm{Ca}^{2+}$ dependence of the mammalian $\alpha 4 \beta 2$ acetylcholine response," Journal of Physiology, vol. 550, no. 1, pp. 11-26, 2003.

[257] N. O. Rodrigues-Pinguet, T. J. Pinguet, A. Figl, H. A. Lester, and B. N. Cohen, "Mutations linked to autosomal dominant nocturnal frontal lobe epilepsy affect allosteric $\mathrm{Ca}^{2+}$ activation of the 42 nicotinic acetylcholine receptor," Molecular Pharmacology, vol. 68, no. 2, pp. 487-501, 2005.

[258] W. Feller, An Introduction To Probability Theory and Its Applications, Wiley and Sons, New York, NY, USA, 3rd edition, 1968.

[259] C. Mulle, D. Choquet, H. Korn, and J. P. Changeux, "Calcium influx through nicotinic receptor in rat central neurons: its relevance to cellular regulation," Neuron, vol. 8, no. 1, pp. 135-143, 1992.

[260] S. Vernino, M. Amador, C. W. Luetje, J. Patrick, and J. A. Dani, "Calcium modulation and high calcium permeability of neuronal nicotinic acetylcholine receptors," Neuron, vol. 8, no. 1, pp. 127-134, 1992.

[261] B. Buisson, M. Gopalakrishnan, S. P. Arneric, J. P. Sullivan, and D. Bertrand, "Human $\alpha 4 \beta 2$ neuronal nicotinic acetylcholine receptor in HEK 293 cells: a patch-clamp study," Journal of Neuroscience, vol. 16, no. 24, pp. 7880-7891, 1996.

[262] J. L. Galzi, S. Bertrand, P. J. Corringer, J. P. Changeux, and D. Bertrand, "Identification of calcium binding sites that regulate potentiation of a neuronal nicotinic acetylcholine receptor," EMBO Journal, vol. 15, no. 21, pp. 5824-5832, 1996.

[263] J. Y. F. Wong, S. A. Ross, C. McColl et al., "Proconvulsantinduced seizures in $\alpha 4$ nicotinic acetylcholine receptor subunit knockout mice," Neuropharmacology, vol. 43, no. 1, pp. 55-64, 2002.

[264] Y. Teper, D. Whyte, E. Cahir et al., "Nicotine-induced dystonic arousal complex in a mouse line harboring a human autosomal-dominant nocturnal frontal lobe epilepsy mutation," Journal of Neuroscience, vol. 27, no. 38, pp. 10128-10142, 2007.

[265] X. Peng, V. Gerzanich, R. Anand, P. J. Whiting, and J. Lindstrom, "Nicotine-induced increase in neuronal nicotinic receptors results from a decrease in the rate of receptor turnover," Molecular Pharmacology, vol. 46, no. 3, pp. 523530, 1994.

[266] M. Gopalakrishnan, E. J. Molinari, and J. P. Sullivan, "Regulation of human $\alpha 4 / \beta 2$ neuronal nicotinic acetylcholine receptors by cholinergic channel ligands and second messenger pathways," Molecular Pharmacology, vol. 52, no. 3, pp. 524534, 1997.
[267] P. Whiteaker, C. G. V. Sharples, and S. Wonnacott, "Agonistinduced up-regulation of $\alpha 4 \beta 2$ nicotinic acetylcholine receptors in M10 cells: pharmacological and spatial definition," Molecular Pharmacology, vol. 53, no. 5, pp. 950-962, 1998.

[268] C. Labarca, J. Schwarz, P. Deshpande et al., "Point mutant mice with hypersensitive $\alpha 4$ nicotinic receptors show dopaminergic deficits and increased anxiety," Proceedings of the National Academy of Sciences of the United States of America, vol. 98, no. 5, pp. 2786-2791, 2001.

[269] C. Fonck, R. Nashmi, P. Deshpande et al., "Increased sensitivity to agonist-induced seizures, straub tail, and hippocampal theta rhythm in knock-in mice carrying hypersensitive $\alpha 4$ nicotinic receptors," Journal of Neuroscience, vol. 23, no. 7, pp. 2582-2590, 2003.

[270] A. R. Tapper, S. L. McKinney, R. Nashmi et al., "Nicotine activation of $\alpha 4^{*}$ receptors: sufficient for reward, tolerance, and sensitization," Science, vol. 306, no. 5698, pp. 1029-1032, 2004.

[271] C. Fonck, B. N. Cohen, R. Nashmi et al., "Novel seizure phenotype and sleep disruptions in knock-in mice with hypersensitive $\alpha 4^{*}$ nicotinic receptors," Journal of Neuroscience, vol. 25, no. 49, pp. 11396-11411, 2005.

[272] G. Zhu, M. Okada, S. Yoshida et al., "Rats harboring S284L Chrna4 mutation show attenuation of synaptic and extrasynaptic GABAergic transmission and exhibit the nocturnal frontal lobe epilepsy phenotype," Journal of Neuroscience, vol. 28, no. 47, pp. 12465-12476, 2008.

[273] M. Avoli, J. Louvel, R. Pumain, and R. Köhling, "Cellular and molecular mechanisms of epilepsy in the human brain," Progress in Neurobiology, vol. 77, no. 3, pp. 166-200, 2005.

[274] J. L. Noebels, "Genetic models of epilepsy," in Epilepsy. A Comprehensive Textbook, J. Engel Jr. and T. A. Pedley, Eds., pp. 445-455, Lippincott Williams and Wilkins, Philadelphia, $\mathrm{Pa}$, USA, 2nd edition, 2008.

[275] J. Xu, B. N. Cohen, Y. Zhu et al., "Altered activity-rest patterns in mice with a human autosomal-dominant nocturnal frontal lobe epilepsy mutation in the $\beta 2$ nicotinic receptor," Molecular Psychiatry, vol. s16, pp. 1048-1061, 2011.

[276] I. Manfredi, A. D. Zani, L. Rampoldi et al., "Expression of mutant $\beta 2$ nicotinic receptors during development is crucial for epileptogenesis," Human Molecular Genetics, vol. 18, no. 6, pp. 1075-1088, 2009.

[277] M. Gossen and H. Bujard, "Tight control of gene expression in mammalian cells by tetracycline- responsive promoters," Proceedings of the National Academy of Sciences of the United States of America, vol. 89, no. 12, pp. 5547-5551, 1992.

[278] P. Tinuper, F. Bisulli, F. Provini, P. Montagna, and E. Lugaresi, "Nocturnal frontal lobe epilepsy: new pathophysiological interpretations," Sleep Medicine, vol. 12, supplement 2, pp. S39-S42, 2011.

[279] R. J. Douglas and K. A. C. Martin, "Neuronal circuits of the neocortex," Annual Review of Neuroscience, vol. 27, pp. 419451, 2004.

[280] R. Ferrari, N. Le Novère, M. R. Picciotto, J. P. Changeux, and M. Zoli, "Acute and long-term changes in the mesolimbic dopamine pathway after systemic or local single nicotine injections," European Journal of Neuroscience, vol. 15, no. 11, pp. 1810-1818, 2002.

[281] M. Fedi, S. F. Berkovic, I. E. Scheffer et al., "Reduced striatal D1 receptor binding in autosomal dominant nocturnal frontal lobe epilepsy," Neurology, vol. 71, no. 11, pp. 795-798, 2008.

[282] M. Galarreta and S. Hestrin, "A network of fast-spiking cells in the neocortex connected by electrical synapses," Nature, vol. 402, no. 6757, pp. 72-75, 1999. 
[283] J. R. Gibson, M. Belerlein, and B. W. Connors, "Two networks of electrically coupled inhibitory neurons in neocortex," Nature, vol. 402, no. 6757, pp. 75-79, 1999.

[284] M. Galarreta and S. Hestrin, "Electrical and chemical synapses among parvalbumin fast-spiking GABAergic interneurons in adult mouse neocortex," Proceedings of the National Academy of Sciences of the United States of America, vol. 99, no. 19, pp. 12438-12443, 2002.

[285] B. Sutor and G. Zolles, "Neuronal nicotinic acetylcholine receptors and autosomal dominant nocturnal frontal lobe epilepsy: a critical review," Pflugers Archiv European Journal of Physiology, vol. 442, no. 5, pp. 642-651, 2001.

[286] P. B. Crino, "Development of cortical excitability," in Epilepsy. A Comprehensive Textbook, J. Engel Jr and T. A. Pedley, Eds., pp. 385-391, Lippincott Williams and Wilkins, Philadelphia, Pa, USA, 2008.

[287] P. Eriksson, E. Ankarberg, and A. Fredriksson, "Exposure to nicotine during a defined period in neonatal life induces permanent changes in brain nicotinic receptors and in behaviour of adult mice," Brain Research, vol. 853, no. 1, pp. 41-48, 2000.

[288] P. Rakic, "The radial edifice of cortical architecture: from neuronal silhouettes to genetic engineering," Brain Research Reviews, vol. 55, no. 2, pp. 204-219, 2007.

[289] E. Bruel-Jungerman, P. J. Lucassen, and F. Francis, "Cholinergic influences on cortical development and adult neurogenesis," Behavioural Brain Research, vol. 221, no. 2, pp. 379-388, 2011.

[290] H. D. Mansvelder and L. W. Role, "Neuronal receptors for nicotine: functional diversity and developmental changes," in Brain Development. Normal Processes and the Effects of Alcohol and Nicotine, M. W. Miller, Ed., pp. 341-362, Oxford University Press, Oxford, UK, 2006.

[291] N. Mechawar, K. C. Watkins, and L. Descarries, "Ultrastructural features of the acetylcholine innervation in the developing parietal cortex of rat," Journal of Comparative Neurology, vol. 443, no. 3, pp. 250-258, 2002.

[292] M. Cordero-Erausquin, L. M. Marubio, R. Klink, and J. P. Changeux, "Nicotinic receptor function: new perspectives from knockout mice," Trends in Pharmacological Sciences, vol. 21, no. 6, pp. 211-217, 2000.

[293] Z. Liu, R. A. Neff, and D. K. Berg, "Sequential interplay of nicotinic and GABAergic siqnaling guides neuronal development," Science, vol. 314, no. 5805, pp. 1610-1613, 2006.

[294] C. Rivera, J. Voipio, J. A. Payne et al., “The $\mathrm{K}^{+} / \mathrm{Cl}^{-}$co-transporter KCC2 renders GABA hyperpolarizing during neuronal maturation," Nature, vol. 397, no. 6716, pp. 251-255, 1999.

[295] C. Rivera, J. Voipio, J. Thomas-Crusells et al., "Mechanism of activity-dependent downregulation of the neuron-specific $\mathrm{K}-\mathrm{Cl}$ cotransporter KCC2," Journal of Neuroscience, vol. 24, no. 19, pp. 4683-4691, 2004.

[296] C. Takayama and Y. Inoue, "Developmental localization of potassium chloride co-transporter 2 (KCC2), GABA and vesicular GABA transporter (VGAT) in the postnatal mouse somatosensory cortex," Neuroscience Research, vol. 67, no. 2, pp. 137-148, 2010.

[297] S. Ge, E. L. K. Goh, K. A. Sailor, Y. Kitabatake, G. L. Ming, and H. Song, "GABA regulates synaptic integration of newly generated neurons in the adult brain," Nature, vol. 439, no. 7076, pp. 589-593, 2006.

[298] F. Picard, S. Baulac, P. Kahane et al., "Dominant partial epilepsies. A clinical, electrophysiological and genetic study of 19 European families," Brain, vol. 123, no. 6, pp. 1247$1262,2000$.
[299] A. Oldani, M. Manconi, M. Zucconi, C. Martinelli, and L. Ferini-Strambi, "Topiramate treatment for nocturnal frontal lobe epilepsy," Seizure, vol. 15, no. 8, pp. 649-652, 2006.

[300] G. P. Raju, D. P. Sarco, A. Poduri, J. J. Riviello, A. M. R. Bergin, and M. Takeoka, "Oxcarbazepine in children with nocturnal frontal-lobe epilepsy," Pediatric Neurology, vol. 37, no. 5, pp. 345-349, 2007.

[301] A. Romigi, M. G. Marciani, F. Placidi et al., "Oxcarbazepine in nocturnal frontal-lobe epilepsy: a further interesting report," Pediatric Neurology, vol. 39, no. 4, p. 298, 2008.

[302] P. Lloyd, G. Flesch, and W. Dieterle, "Clinical pharmacology and pharmacokinetics of oxcarbazepine," Epilepsia, vol. 35, no. 3, pp. S10-S13, 1994.

[303] E. S. Tecoma, “Oxcarbazepine," Epilepsia, vol. 40, no. 5, pp. S37-S46, 1999.

[304] S. I. Johannessen, D. Battino, D. J. Berry et al., "Therapeutic drug monitoring of the newer antiepileptic drugs," Therapeutic Drug Monitoring, vol. 25, no. 3, pp. 347-363, 2003.

[305] R. L. Macdonald and M. A. Rogawski, "Cellular effects of antiepileptic drugs," in Epilepsy. A Comprehensive Textbook, J. Engel Jr. and T. A. Pedley, Eds., pp. 1433-1445, Lippincott Williams and Wilkins, Philadelphia, Pa, USA, 2nd edition, 2008.

[306] M. J. McLean and R. L. Macdonald, "Carbamazepine and 10,11-epoxycarbamazepine produce use- and voltagedependent limitation of rapidly firing action potentials of mouse central neurons in cell culture," Journal of Pharmacology and Experimental Therapeutics, vol. 238, no. 2, pp. 727$738,1986$.

[307] J. R. Schwarz and G. Grigat, "Phenytoin and carbamazepine: potential- and frequency-dependent block of $\mathrm{Na}$ currents in mammalian myelinated nerve fibers," Epilepsia, vol. 30, no. 3, pp. 286-294, 1989.

[308] J. Benes, A. Parada, A. A. Figueiredo et al., "Anticonvulsant and sodium channel-blocking properties of novel 10,11dihydro-5H-dibenz[b,f]azepine-5-carboxamide derivatives," Journal of Medicinal Chemistry, vol. 42, no. 14, pp. 25822587, 1999.

[309] C. Zona, M. T. Ciotti, and M. Avoli, "Topiramate attenuates voltage-gated sodium currents in rat cerebellar granule cells," Neuroscience Letters, vol. 231, no. 3, pp. 123-126, 1997.

[310] G. Curia, P. Aracri, E. Colombo et al., "Phosphorylation of sodium channels mediated by protein kinase- $\mathrm{C}$ modulates inhibition by topiramate of tetrodotoxin-sensitive transient sodium current," British Journal of Pharmacology, vol. 150, no. 6, pp. 792-797, 2007.

[311] F. Picard, S. Bertrand, O. K. Steinlein, and D. Bertrand, "Mutated nicotinic receptors responsible for autosomal dominant nocturnal frontal lobe epilepsy are more sensitive to carbamazepine," Epilepsia, vol. 40, no. 9, pp. 1198-1209, 1999.

[312] C. Zheng, K. Yang, Q. Liu et al., "The anticonvulsive drug lamotrigine blocks neuronal $\alpha 4 \beta 2$ nicotinic acetylcholine receptors," Journal of Pharmacology and Experimental Therapeutics, vol. 335, no. 2, pp. 401-408, 2010. 

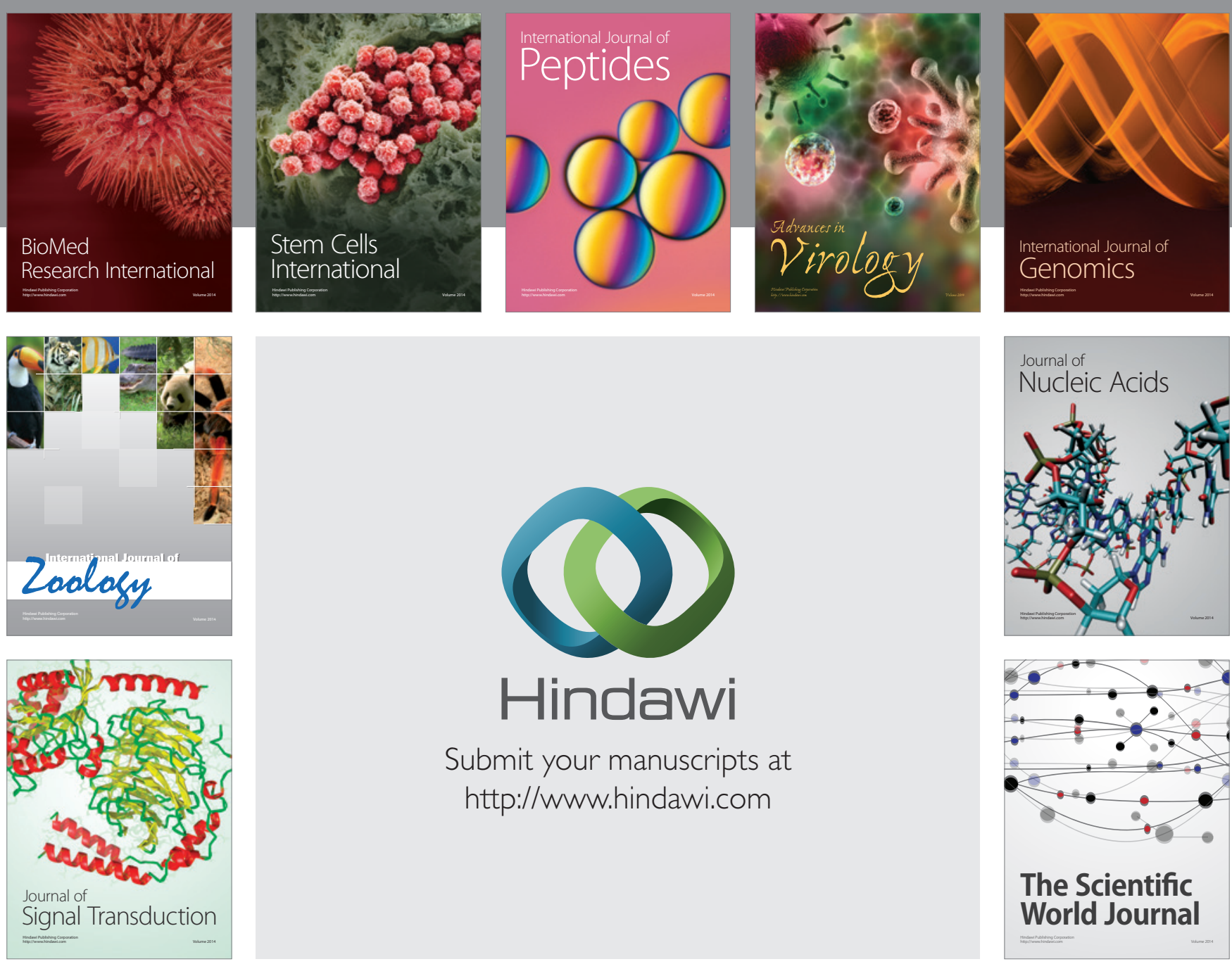

Submit your manuscripts at

http://www.hindawi.com
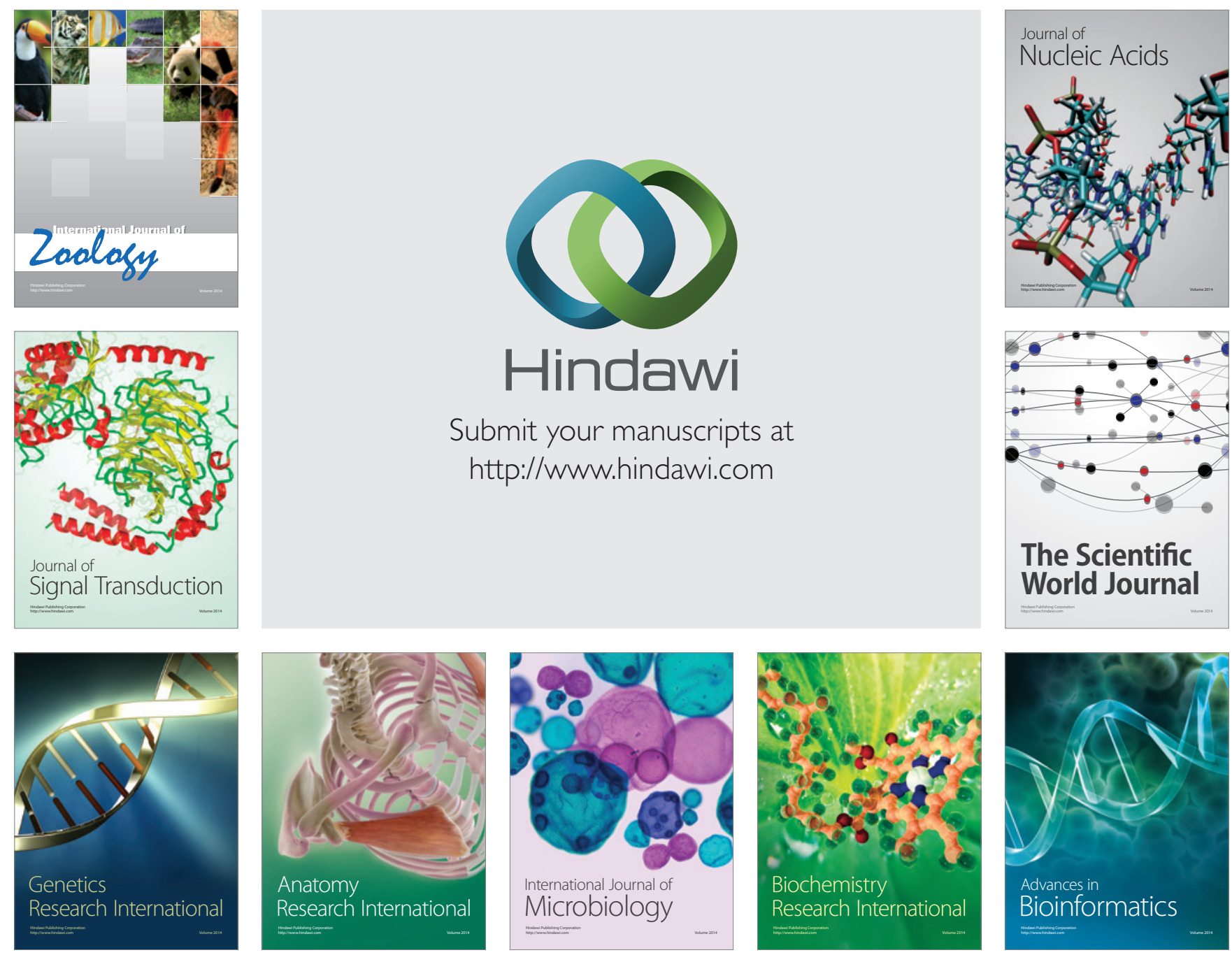

The Scientific World Journal
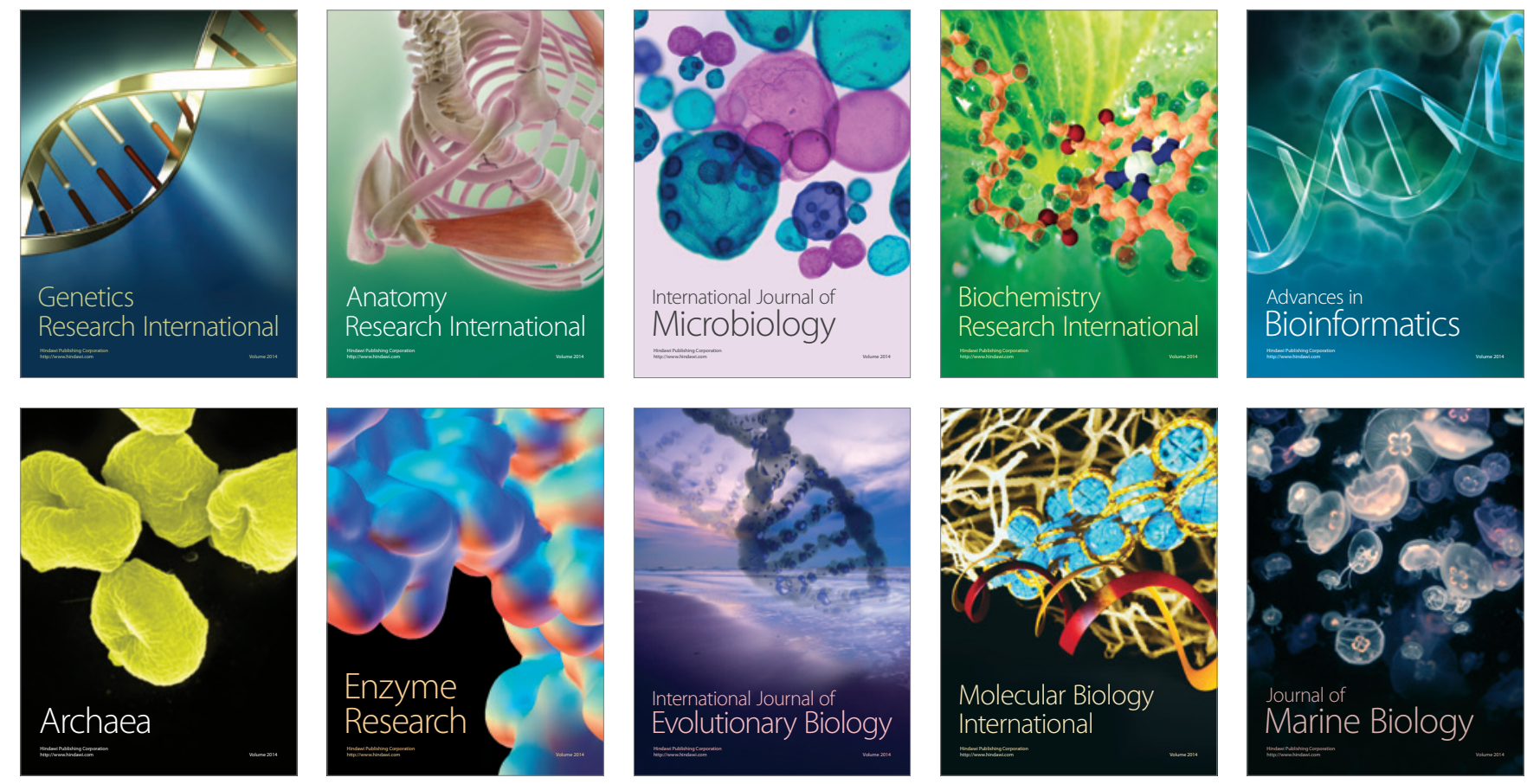